\title{
Grain sizes of susceptibility and anhysteretic remanent magnetization carriers in Chinese loess/paleosol sequences
}

\author{
Qingsong Liu, ${ }^{1}$ Subir K. Banerjee, ${ }^{1}$ Michael J. Jackson, ${ }^{1}$ Barbara A. Maher, ${ }^{2}$ \\ Yongxin Pan, ${ }^{3}$ Rixiang Zhu, ${ }^{3}$ Chenglong Deng, ${ }^{3}$ and Fahu Chen ${ }^{4}$ \\ Received 19 August 2003; revised 5 January 2004; accepted 14 January 2004; published 6 March 2004.
}

[1] Detailed rock magnetic studies show that susceptibility (mass-specific $\chi$ ) and anhysteretic remanent magnetization (ARM) of the Chinese loess/paleosol sequences are carried by almost identical magnetic carriers. Therefore the ratio $\Delta \chi^{\prime} \chi_{\text {ARM }}$ (or equivalently $\chi_{\mathrm{ARM}} / \Delta \chi$, where $\Delta \chi$ is defined as $\chi-\chi_{0}$, and $\chi_{0}$ is the intercept susceptibility of the plot of $\chi$ versus ARM, and $\chi_{\text {ARM }}$ is field-normalized ARM) can be used to quantify the grain size of $\chi$ and ARM carriers. By determining this ratio for three Chinese loess/paleosol profiles (Jiuzhoutai, Yuanbao, and Yichuan) characterized by different degrees of environmentally controlled pedogenesis and sedimentation rates, we show that the lower grain-size limit of aeolian magnetic particles in the less pedogenically altered loess units is about $100-300 \mathrm{~nm}$, in the finer-grained pseudosingle domain (PSD) grain-size range. In contrast, the grain sizes of pedogenically produced magnetic particles for mature paleosols dominantly cover both the superparamagnetic (SP) and single-domain (SD) ranges. On the basis of plots of $\Delta \chi / \chi_{\text {ARM }}$ against $\Delta \chi$, samples can be divided into four regions (I, II, III, and IV). Region I corresponds to the least pedogenically altered primary loess samples, with $\Delta \chi^{\prime} \chi_{\text {ARM }}$ of $0.165-0.24$. Samples in region II, a transition zone between the least altered loess and the onset of development of paleosols, have $\chi$ values identical to those in region I but have lower $\Delta \chi / \chi_{\text {ARM }}$ of $0.09-0.165$. With increasing susceptibility in zone III, $\Delta \chi / \chi_{\text {ARM }}$ is positively correlated with $\Delta \chi$, indicating the gradually increasing influence of SP particles. Finally, in zone IV with $\Delta x$ higher than $\sim 6.5 \times 10^{-7} \mathrm{~m}^{3} \mathrm{~kg}^{-1}, \Delta \chi / \chi_{\text {ARM }}$ is independent of the variations in $\Delta \chi$, suggesting that $\Delta \chi^{\prime} \chi_{\text {ARM }}$ is totally controlled by the pedogenic finest-grained particles and the size distribution of these particles remains almost constant. The development of soils in the Chinese loess revealed by these three profiles from three sites can be clearly explained by a continuous process of pedogenesis, increasing from zone I to zone IV. The definition of the pedogenic zones can help to improve our understanding of the underlying mechanisms and variability of pedogenesis and thus could enable more successful and accurate separation of the authentic pedogenic signals from the background signal of the aeolian inputs at different loess sites worldwide. INDEX TERMS: 1512

Geomagnetism and Paleomagnetism: Environmental magnetism; 1519 Geomagnetism and Paleomagnetism: Magnetic mineralogy and petrology; 1540 Geomagnetism and Paleomagnetism: Rock and mineral magnetism; KEYWORDS: Chinese loess, grain size of susceptibility and ARM carriers, pedogenesis

Citation: Liu, Q., S. K. Banerjee, M. J. Jackson, B. A. Maher, Y. Pan, R. Zhu, C. Deng, and F. Chen (2004), Grain sizes of susceptibility and anhysteretic remanent magnetization carriers in Chinese loess/paleosol sequences, J. Geophys. Res., 109, B03101, doi:10.1029/2003JB002747.

\footnotetext{
${ }^{1}$ Institute for Rock Magnetism, Department of Geology and Geophysics, University of Minnesota, Minneapolis, Minnesota, USA.

${ }^{2}$ Centre for Environmental Magnetism and Palaeomagnetism, Lancaster Environment Center, Geography Department, Lancaster University, Lancaster, UK.

${ }^{3}$ Paleomagnetism Laboratory, Institute of Geology and Geophysics, Chinese Academy of Sciences, Beijing, China.

${ }^{4}$ Center for Arid Environment and Paleoclimate Research, College of Earth and Environment Science, University of Lanzhou, Lanzhou, China.

Copyright 2004 by the American Geophysical Union. 0148-0227/04/2003JB002747\$09.00
}

\section{Introduction}

[2] The global loess/paleosol sequences are of great interest as paleoclimatic archives. Especially, the Chinese loess/paleosols provide a nearly continuous record of both paleoclimatic [Heller and Liu, 1986; Kukla et al., 1988; Maher and Thompson, 1991, 1992, 1995; Banerjee and Hunt, 1993; An and Porter, 1997; Liu et al., 1999a; Ding et al., 2002] and paleomagnetic variations [Heller and Liu, 1982, 1984; Heller and Evans, 1995; Guo et al., 1999; Zhu et al., 1999; Evans and Heller, 2001; Pan et al., 2001] over the last 2.5 million years. Among various paleoclimatic proxies, low-field magnetic susceptibility ( $\chi$, normalized by 
mass, or $k$ by volume) is the most commonly measured parameter because it is fast, inexpensive, and nondestructive, and it has been used to establish the pedostratigraphy of the loess sequences, and further to correlate with variations in marine oxygen isotope records [Heller and Liu, 1984, 1986; Kukla et al., 1988].

[3] The nature of links between climate and susceptibility is, in fact, site-specific or paleoenvironmentally dependent [Maher, 1998]. For example, the Chinese paleosols are characterized by higher susceptibility than the less weathered loess counterparts [Heller and Liu, 1982, 1984, 1986], whereas in Alaska [Beget et al., 1990; Lagroix and Banerjee, 2002], Argentina [Nabel, 1993; Schellenberger et al., 2003], and Siberia [Chlachula et al., 1998; Zhu et al., 2000, 2003], the opposite pattern was observed, namely, the paleosol units correspond to a lower susceptibility. Even in the Chinese loess plateau, this opposite pattern has also been discovered, e.g., at Tailai, at the northeastern margin of the plateau [Sun and Liu, 2000], probably due to a relatively cold/dry paleoenvironment similar to Siberia's. Maher [1998] proposed that the links between susceptibility and paleoclimate are highly dependent on the degree of development and preservation of pedogenic grains. Therefore, to better understand these different pedogenically controlled magnetic signals at different sites, it is essential to accurately determine the variations in not only the mineralogy, but also the granulometry (grain-size distribution) of magnetic minerals along the pathways of susceptibility enhancements (e.g., a complete transition zone from loess to paleosol).

[4] The enhancement of susceptibility for the Chinese loess/paleosol sequences has been previously interpreted in terms of several mechanisms, e.g., depositional dilution of a constant flux of tropospheric ultrafine magnetic particles during glacial periods [Kukla et al., 1988; Porter, 2001], physical enrichment of magnetic minerals in paleosols due to decalcification and soil compaction [Heller and Liu, 1984], and pedogenic production of superparamagnetic (SP, <40 nm) particles [Zhou et al., 1990; Maher and Thompson, 1991; Banerjee and Hunt, 1993]. However, with excessive paleoprecipitation or in unfavorable redox environments, magnetic depletion has also been proposed by Maher [1998] and Liu et al. [1999a, 1999b, 2003, and references therein].

[5] However, most loess researchers accept that the susceptibility (and anhysteretic remanent magnetization, ARM) enhancement in the Chinese loess and paleosols is contributed primarily by what have been termed SP/viscous particles spanning the SP to the thermally stable singledomain (SD) threshold, up to about $50 \mathrm{~nm}$ in size as described by Maher and Thompson [1991, 1992]. Furthermore, both Forster and Heller [1997] and Maher and Thompson [1999] have discussed different enhancement pathways, whereby different regions of the Loess Plateau demonstrate different degrees of magnetic "hardness" or "softness," depending on the relative amounts of nonviscous SD and viscous SP particles produced pedogenically.

[6] Even though these earlier studies have provided a general framework for interpretation of susceptibility enhancement of the Chinese loess/paleosol sequences, efforts are still necessary to focus on the following unresolved or incompletely understood topics. The first one involves the initial grain-size distribution of the magnetic particles in the less pedogenically altered loess units. This distribution is the baseline for further considering the postdepositional pedogenic effects. In particular, it will be useful to determine the lower grain-size limit of aeolian magnetite/maghemite. The second topic stresses the exact grain size of the magnetic grains responsible for susceptibility enhancement. In paleosols, both SP and SD, even pseudosingle domain (PSD) magnetic grains are abundant [Sun et al., 1995; Hunt et al., 1995]. Therefore accurately determining the exact carriers of magnetic susceptibility of the Chinese loess/ paleosol sequences is of particular importance for understanding pedogenic mechanisms, and for precisely quantifying the pedogenic magnetic products separately from the aeolian inputs to retrieve accurate records of paleoclimatic fluctuations (e.g., paleorainfall). The third topic is whether there is a consistent model for the pedogenic pathways at different sites with different paleoenviromental conditions including China, Europe, Alaska, and Argentina. Even though relationships between coercivities and susceptibility have been suggested to define the pedogenic pathways for different profiles, recent studies have shown that coercivities are not solely affected by pedogenically controlled grain sizes but are also strongly affected by oxidation degrees and nonstoichiometry of the magnetic particles in samples [van Velzen and Dekkers, 1999].

[7] To detect the systematic changes in grain sizes of both aeolian and pedogenic grains during pedogenesis, the following rock magnetic approaches have been widely used: plots of $M_{\mathrm{rs}} / M_{\mathrm{s}}$ against $H_{\mathrm{cr}} / H_{\mathrm{c}}$ (named "Day plots" [Day et al., 1977; Dunlop, 2002a, 2002b]); plots of $\chi_{\text {ARM }}$ and $\chi$ ( $\chi_{\text {ARM }}$ is the DC field-normalized anhysteretic remanent magnetization, ARM [Banerjee et al., 1981; King et al., 1982; Özdemir and Banerjee, 1982; Evans and Heller, 2003]); and ratio of $\chi /$ SIRM (where SIRM is saturation isothermal remanent magnetization [Maher, 1988]). Among these methods, the Day plot [Day et al., 1977] is useful for estimating only the average grain size of magnetic minerals in a whole sample, because these hysteretic parameters reflect contributions of all particles in a sample. Therefore the presence of multiple mineral phases and grain size populations in a sample as well as their nonstoichiometry can lead to serious ambiguities [Dunlop, 2002a, 2002b]. For the application of the biparametric ratios (e.g., $\chi / S I R M$ and $\chi$ /ARM), the prerequisite is that the related parameters all have to be carried by a single dominant magnetic carrier. However, this restriction has not been well or explicitly considered in previous studies [e.g., Thompson et al., 1980; King et al., 1982; Zhou et al., 1990; Maher and Thompson, 1991, 1992], especially for the loess/paleosol sequences, which are characterized by broad grain-size distributions and mixed magnetic mineralogy.

[8] In this study, we first systematically test for the consistency of the magnetic carriers of $\chi$, SIRM and ARM. Our working hypothesis is that only when the parameters $\chi$, SIRM, and ARM are all due to identical carriers, can we determine a reliable ratio (e.g., $\chi / \chi_{\text {ARM }}$ ) to quantify the grain size of magnetic particles in samples. If two related parameters are carried by the same population of grains (both mineralogy and granulometry), then we can expect predictable and coherent changes with temperature due to mineral transformations during the thermal treat- 


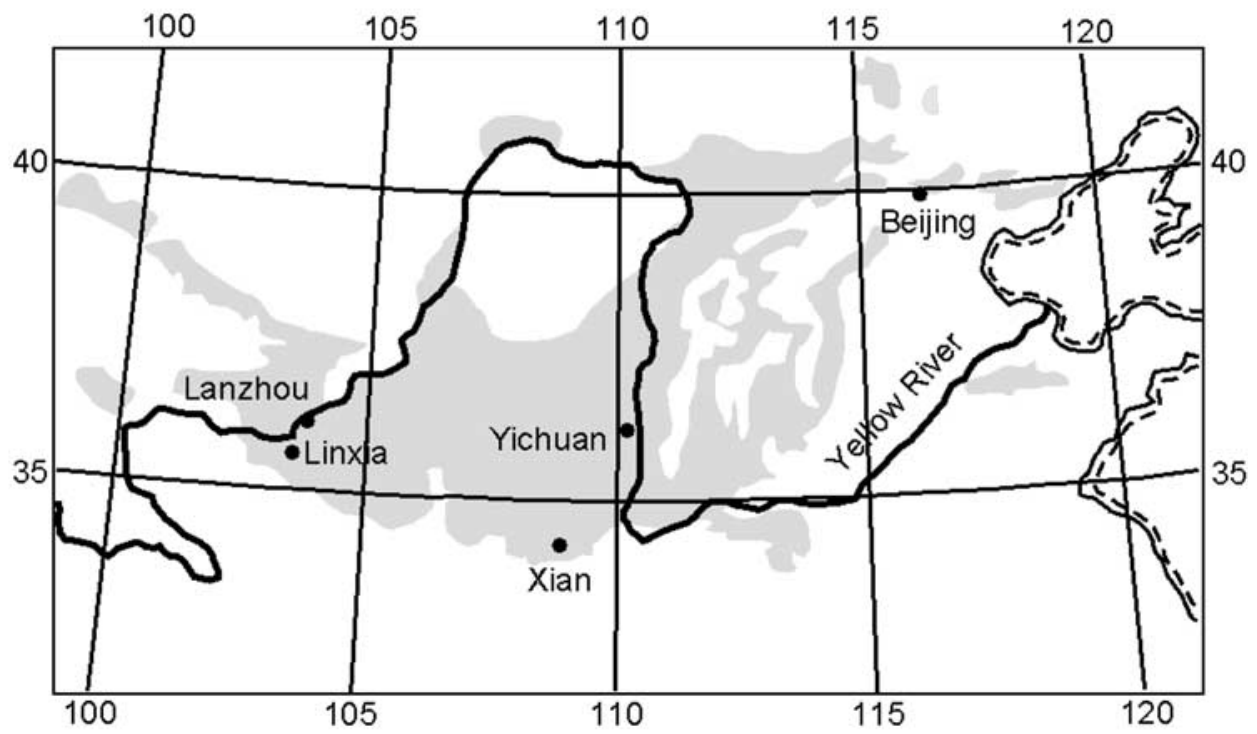

Figure 1. Sketch map of the Chinese loess plateau and locations of the studied sites. Yichuan (YC) $\left(36^{\circ} 03^{\prime} \mathrm{N} / 110^{\circ} 10^{\prime} \mathrm{E}\right)$ is located about $300 \mathrm{~km}$ northeast of $\mathrm{Xi}$ 'an in the central part of the Chinese loess plateau. The Jiuzhoutai (JZT) section is located near Lanzhou City $\left(36^{\circ} \mathrm{N} / 103^{\circ} 50^{\prime} \mathrm{E}\right)$, and the Yuanbao (YB) section $\left(35^{\circ} 38^{\prime} \mathrm{N} / 103^{\circ} 10^{\prime} \mathrm{E}\right)$ is located on the fourth terrace of the Daxia River in the Linxia Basin.

ments. Conversely, we would expect inconsistent trends if the two parameters are controlled by different carriers.

[9] After carefully scrutinizing the thermal behavior of $\chi$, $\mathrm{ARM}_{\mathrm{Re}}$ and $\mathrm{SIRM}_{\mathrm{Re}}$ (to be defined later), we used the ratio $\chi / \chi_{\text {ARM }}$ as a grain-size indicator for the Chinese loess/ paleosol sequences. Constrained by the observed variations in $\Delta \chi / \chi_{\text {ARM }}$ (where $\Delta \chi$ is the background-corrected $\chi$ ) from three Chinese loess profiles with distinct pedogenesis and depositional rates, we systematically investigate changes in the grain-size distributions of their aeolian and pedogenic grains. Then the "pathways" of the paleosol developments (represented by the different degrees of susceptibility enhancements, and not necessarily the exact chemical pathways of pedogenesis) will be systematically examined based on a biplot of $\Delta \chi / \chi_{\text {ARM }}$ and $\Delta \chi$.

[10] Even though this study focuses on the Chinese loess/ paleosol sequences, our long-term goal aims to extend our method to the loess profiles with opposite susceptibility patterns. This will broaden our understanding of pedogenesis. For example, we could provide further constraints on the "puzzle" whether the differences of pedogenesis at different profiles reflect a different stage of a consistent pedogenic model [Maher, 1998], or totally different processes [Evans, 2001].

\section{Sampling}

[11] In this study, we examined the following three profiles: Yichuan (YC), Yuanbao (YB), and Jiuzhoutai (JZT) (Figure 1). The YB and JZT profiles, separated by $60 \mathrm{~km}$, are located in the western part of the Chinese loess plateau with lower pedogenesis and higher sedimentation rates, whereas the $\mathrm{YC}$ profile, $\sim 500 \mathrm{~km}$ east of the $\mathrm{YB}$ section, is located in the central part of the loess plateau with higher pedogenesis and lower sedimentation rate.

[12] The YC loess section $\left(36^{\circ} 03^{\prime} \mathrm{N} / 110^{\circ} 10^{\prime} \mathrm{E}\right)$ is located about $300 \mathrm{~km}$ northeast of Xian [Liu et al., 2002]. The total thickness of the profile deposited since beginning of the last interglacial period is about $12 \mathrm{~m}$. The last interglacial paleosol S1 and the last glacial loess L1 are located in the intervals $12.0-8.8 \mathrm{~m}$, and $8.8-0.6 \mathrm{~m}$, respectively.

[13] The JZT section is located at the sixth terrace of the Yellow River in Lanzhou City $\left(36^{\circ} \mathrm{N} / 103^{\circ} 50^{\prime} \mathrm{E}\right)$ and is characterized by the lowest pedogenesis of the three sections [Fang et al., 1997, 1999; Kemp et al., 2001]. The $7.4 \mathrm{~m}$ thick paleosol unit S1 (marine isotope stage, MIS 5) is between 28.6 and $36 \mathrm{~m}$. Three widely separated subpaleosol units can be assigned unambiguously as S1S1 (MIS 5a) S1S2 (MIS 5c), and S1S3 (MIS 5e). In this study, we focus on the sandwich units S1L2/S1S3/L2 (Figure 2).

[14] The YB section $\left(35^{\circ} 38^{\prime} \mathrm{N} / 103^{\circ} 10^{\prime} \mathrm{E}\right)$, with intermediate pedogenesis compared to JZT and $\mathrm{YC}$, is located in the northwestern margin of the Chinese loess plateau on the fourth terrace of the Daxia River in the Linxia Basin. The $\sim 8 \mathrm{~m}$ paleosol unit S1 (MIS 5) consists of three welldeveloped subpaleosol units (S1S1, S1S2, and S1S3) and two interbedded subloess layers (S1L1 and S1L2). For a detailed description of the site's pedostratigraphy and chronology, see Chen et al. [1999]. For this profile we also focus on only the S1L2/S1S3/L2 sandwich to investigate pedogenic effects on the distribution of the grain sizes of the magnetic grains spanning a complete climatic cold/warm/cold cycle.

[15] Bag samples were collected at $5 \mathrm{~cm}$ intervals between L1 and S1 from well-exposed outcrops after cleaning about $50 \mathrm{~cm}$ to eliminate the surface weathering effects. All samples were shipped to the University of Minnesota and measured in the Institute for Rock Magnetism.

\section{Experimental Procedures}

[16] The low-field mass-specific magnetic susceptibility $(\chi)$ was first measured with a Kappa Bridge. In the following discussion, the contribution of SP and SD grains to the bulk susceptibility are denoted as $\chi_{S P}$ and $\chi_{S D}$, 


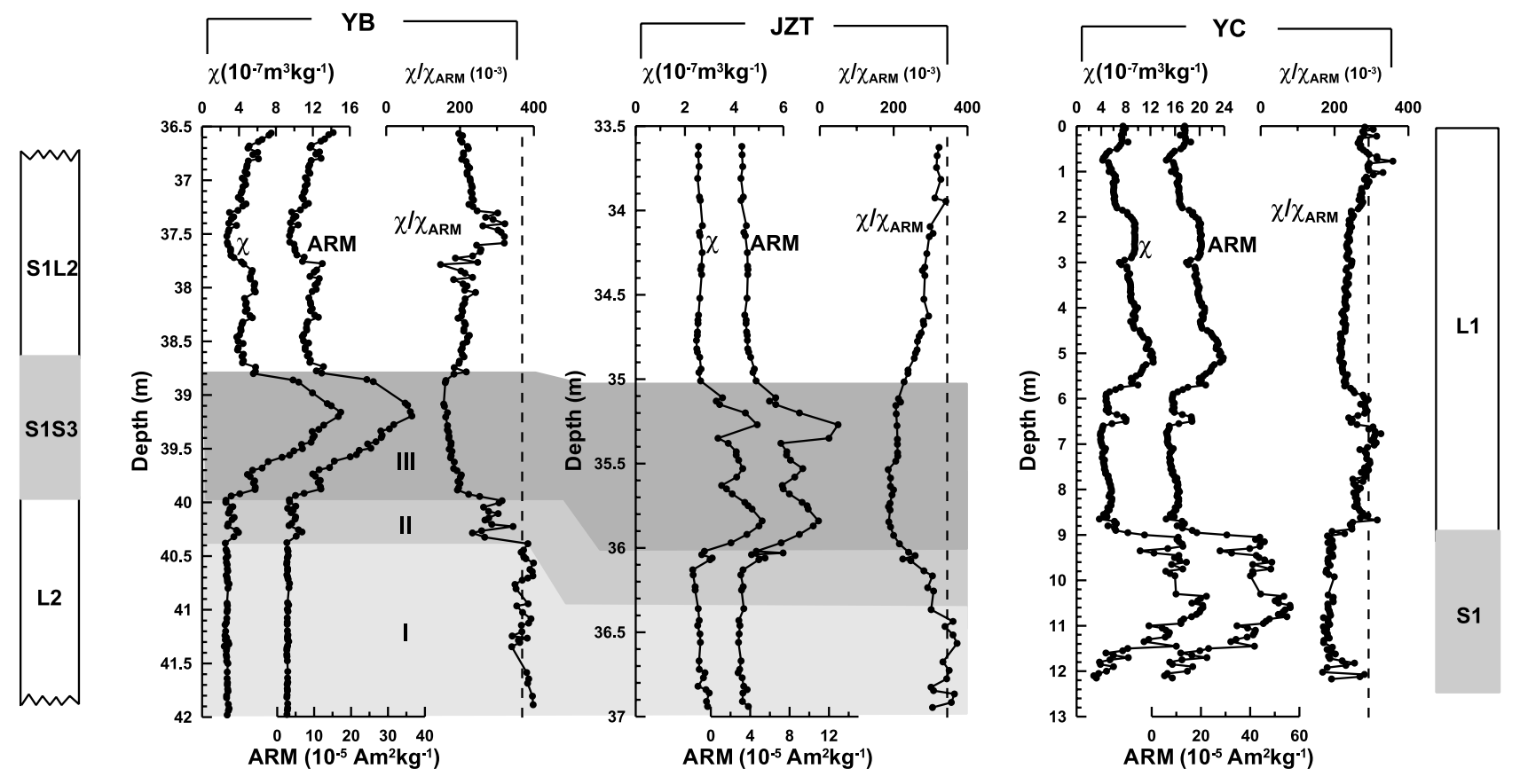

Figure 2. Stratigraphy, $\chi, A R M$, and $\chi / \chi_{A R M}$ of $Y B, Y C$, and JZT. The light gray horizontal bar marks the less pedogenically altered loess units (zone I) with average $\chi / \chi_{\text {ARM }}$ of $0.378 \pm 0.027$ (vertical dashed lines). The dark gray bar (zone III) locates samples of S1S3. Zone II is the transition between zones I and III.

respectively. The detailed notations are summarized in notation section. The stratigraphic boundaries of the section were determined mainly by the susceptibility as well as visual observation during the field work. ARM was imparted in a $200 \mathrm{mT}$ alternating field with a superimposed $50 \mu \mathrm{T}$ direct bias field using a Dtech D2000 instrument. This is also expressed as $\chi_{\text {ARM }}$, after normalizing by the $50 \mu \mathrm{T}$ direct bias field, to compare our results with previous ARM measurements, which have been obtained using different bias fields $(<0.1 \mathrm{mT})$.

[17] On selected loess/paleosol samples, frequency-dependent susceptibility was measured using a LakeShore Cryotronics AC Susceptometer. The parameter $\chi_{\mathrm{fd}} \%$, is generally expressed as $100 \% *\left(\chi_{470 \mathrm{~Hz}}-\chi_{4700 \mathrm{~Hz}}\right) / \chi_{470 \mathrm{~Hz}}$ computed from dual-frequency measurements on Bartington instruments. In this study, $\chi_{\mathrm{fd}} \%$ was calculated more accurately using data acquired at 20 frequencies between 40 and $4000 \mathrm{~Hz}$ at room temperature using a LakeShore susceptometer. Linear regression produced excellent fits to the $\chi(\log (f))$ data, and best fit values for 400 and $4000 \mathrm{~Hz}$ were used for the subsequent calculations. The absolute difference in susceptibility between 400 and $4000 \mathrm{~Hz}$ is defined as $\chi_{\mathrm{fd}}\left(\chi_{400 \mathrm{~Hz}}-\chi_{4000 \mathrm{~Hz}}\right)$.

[18] The $\chi / \chi_{\text {ARM }}$ ratio (dimensionless) is used to investigate relative contributions of SP and SD grains to the bulk signal [Evans and Heller, 2003]. Theoretically, both SP (especially $<20 \mathrm{~nm}$ ) and multidomain (MD) grains are characterized by higher $\chi / \chi_{\text {ARM }}$ ratios compared to $\mathrm{SD} /$ PSD grains, because they carry higher susceptibility but lower ARM (especially, SP grains are supposed not to carry remanence) [Maher, 1988]. The $\mathrm{X} / \mathrm{\chi}_{\mathrm{ARM}}$ ratios for synthetic magnetites (in Figure 3) are from Dankers [1978], Özdemir and Banerjee [1982], and Maher [1988].
[19] For thermal treatments, two selected samples (a loess sample at $34.45 \mathrm{~m}$ from JZT and a mature paleosol sample at $10.55 \mathrm{~m}$ from $\mathrm{YC}$ ) were progressively heated in air from room temperature up to $700^{\circ} \mathrm{C}$ in steps of $25^{\circ} \mathrm{C}$. The samples were held at the treatment temperature $\left(T_{\text {tr }}\right)$ for $30 \mathrm{~min}$, but remanences were measured at room temperature after the samples were cooled down.

[20] To monitor the resulting changes in the magnetic carriers of ARM and SIRM, parallel samples were used to avoid effects of the acquisition history of SIRM on ARM. After each heating, samples were again given a repeat ARM and SIRM at room temperature, referred as to $\mathrm{ARM}_{\mathrm{Re}}$, and SIRM $_{R e}$, respectively. If there are no chemical alterations on the magnetic minerals, $\mathrm{ARM}_{\mathrm{Re}}$ and $\mathrm{SIRM}_{\mathrm{Re}}$ should remain unchanged. Therefore changes in $\mathrm{ARM}_{\mathrm{Re}}$ and $\mathrm{SIRM}_{\mathrm{Re}}$ respectively, reflect concentration variations in ARM and SIRM carriers.

[21] SIRM was acquired in a $1.5 \mathrm{~T}$ field. The room temperature susceptibility of the thermal products was also measured for further comparison. The room temperature remanences (ARM, $\mathrm{ARM}_{\mathrm{Re}}, \mathrm{SIRM}$, and $\mathrm{SIRM}_{\mathrm{Re}}$ ) were measured by a $2 \mathrm{G}$ cryogenic magnetometer.

[22] Hysteresis loops at room temperature were obtained using a Princeton Applied Research vibrating sample magnetometer (VSM). The saturation field is $1 \mathrm{~T}$. Saturation magnetization $\left(M_{S}\right)$, saturation remanence $\left(M_{\mathrm{rs}}\right)$, coercivity $\left(B_{c}\right)$ and coercivity of remanence $\left(B_{\mathrm{cr}}\right)$ were obtained after subtracting the paramagnetic contribution.

[23] To quantify the contribution of each component to the bulk properties, magnetic extracts of the paleosol sample at $39.2 \mathrm{~m}$ and the loess sample at $40.02 \mathrm{~m}$ were obtained in a continuous loop flow driven by a pump, using a highgradient magnet. Each separation ran for about 2 weeks to 

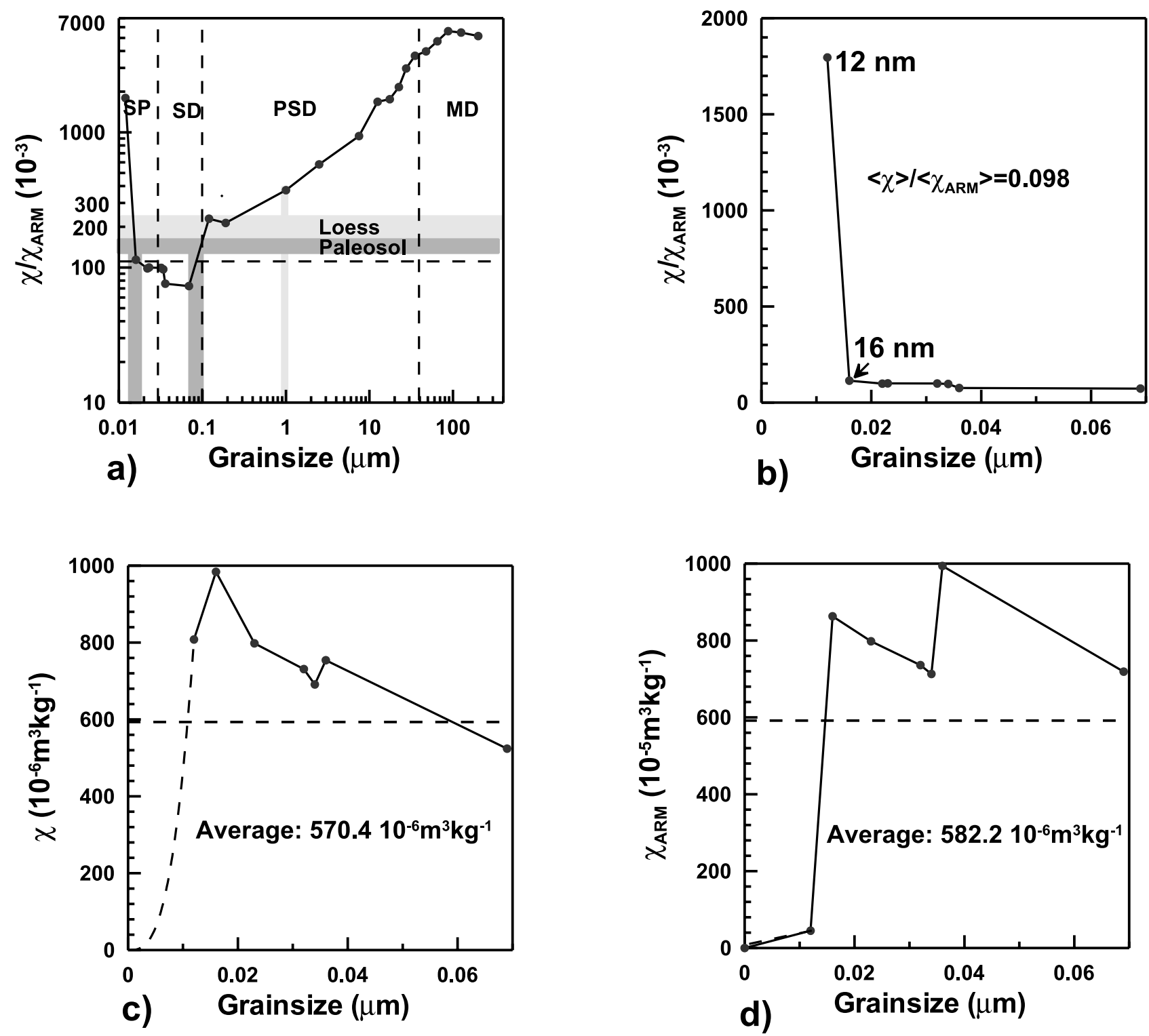

Figure 3. Plot of $\chi / \chi_{\text {ARM }}$ versus grain size for synthetic magnetite ranging (a) from SP to MD and (b) from SP to $70 \mathrm{~nm}$. $\chi_{\text {ARM }}$ is field-normalized ARM. The $\chi / \chi_{\text {ARM }}$ ratios are from Dankers [1978] $(d>$ $1 \mu \mathrm{m}), \ddot{O} z$ demir and Banerjee [1982] $(70 \mathrm{~nm}<d<11 \mu \mathrm{m})$, and Maher [1988] $(d<70 \mathrm{~nm})$. In Figure 3a the light and dark gray bars represent the $\chi^{/} \chi_{\text {ARM }}$ and the corresponding grain-size range of the susceptibility carriers for the less altered loess and mature paleosols, respectively. Vertical dashed lines mark the grain-size boundaries. The horizontal dashed line $\left(\chi^{/} \chi_{\text {ARM }} \approx 0.1\right.$, the lowest value $)$ corresponds to the grain-size range of $20-90 \mathrm{~nm}$. In Figure $3 \mathrm{c}$ the dashed curve shows the theoretical trend $\left(\mathrm{k} \sim \mathrm{d}^{3}, \mathrm{~d}\right.$ is the diameter of the grain) below $12 \mathrm{~nm}$.

sufficiently extract the magnetic minerals from samples. The extraction efficiencies (EE) are estimated by the following equation: $\mathrm{EE}(\%)=100 \%\left(1-\lambda_{\text {residue }}\left(\lambda_{\text {bulk }}\right)\right.$, where $\lambda_{\text {residue }}$ and $\lambda_{\text {bulk }}$ are the parameters ( $\chi$, ARM, and SIRM) of the residue and bulk material, respectively.

\section{Results}

\subsection{The $\chi$ and ARM}

[24] The stratigraphy and depth plots of $\chi$ and ARM are shown in Figure 2. For the YC section, $\chi$ ranges $\sim 2.6-$ $15.0 \times 10^{-7} \mathrm{~m}^{3} \mathrm{~kg}^{-1}$, with the lowest value in the loess units and highest in paleosols. The intermediate values (4$8 \times 10^{-7} \mathrm{~m}^{3} \mathrm{~kg}^{-1}$ ) mainly correspond to the weak subpaleosols between 2 and $6 \mathrm{~m}$, and the boundaries of L1/S1 $(\sim 8.8-9 \mathrm{~m})$ and S1/L2 $(11.6-12 \mathrm{~m})$. The $\chi$ values higher than $8.0 \times 10^{-7} \mathrm{~m}^{3} \mathrm{~kg}^{-1}$ correspond to the mature paleosol S1 unit of the YC section. The mass-normalized ARM nearly duplicates the features of susceptibility variations, and ranges between 37.2 and $403.0 \mu \mathrm{A} \mathrm{m}^{2} \mathrm{~kg}^{-1}$.

[25] The susceptibility of the less altered JZT section is much lower than that of YC. The maximum susceptibility of the paleosol unit S1S3 is only $\sim 5.0 \times 10^{-7} \mathrm{~m}^{3} \mathrm{~kg}^{-1}$, comparable to the loess unit of YC. Therefore, even though 


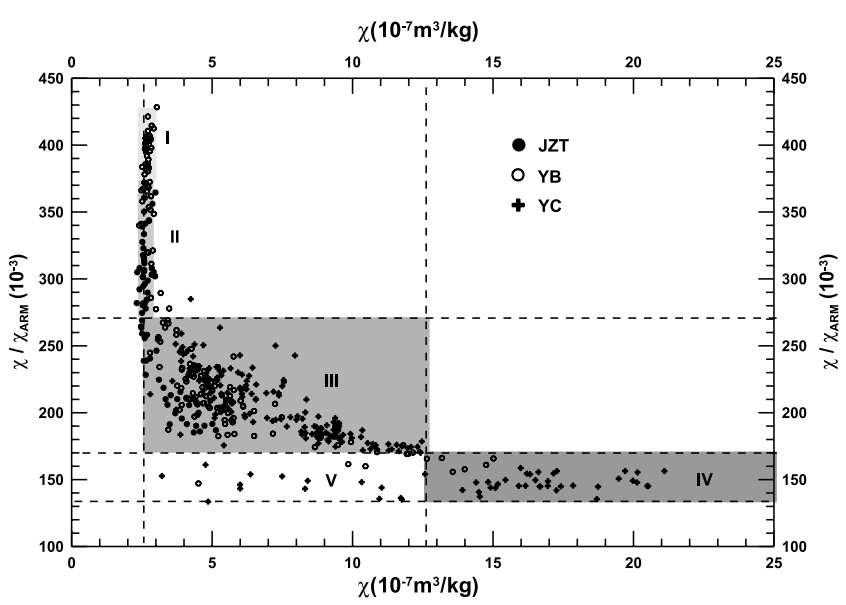

Figure 4. Plot of $\chi / \chi_{\text {ARM }}$ (dimensionless) versus $\chi$ for JZT, YB, and YC samples. Notations of I, II, II, IV, and V point to five regions with distinct rock magnetic properties, and are explained in section 4.2 .

terms "loess" and "paleosol" are convenient for pedostratigraphy, they are imprecise for the comparison of the pathways of the magnetic susceptibility enhancement for these two different profiles. We prefer to use absolute susceptibility values to classify samples as less pedogenically altered loess $\left(<3.0 \times 10^{-7} \mathrm{~m}^{3} \mathrm{~kg}^{-1}\right)$, intermediate $\left(\sim 3.0-12.0 \times 10^{-7} \mathrm{~m}^{3} \mathrm{~kg}^{-1}\right)$, and mature paleosols $\left(>12.0 \times 10^{-7} \mathrm{~m}^{3} \mathrm{~kg}^{-1}\right)$. The ARM variations of the JZT profile also almost duplicate the patterns of susceptibility.

[26] The YB profile has suffered an intermediate degree of pedogenic alteration, more than JZT and less than YC. The maximum $\chi$ of SIS3 at YB is $\sim 15 \times 10^{-7} \mathrm{~m}^{3} \mathrm{~kg}^{-1}$, about three times higher than that of the JZT section. A direct result of the higher pedogenesis is that the triple susceptibility and ARM peaks revealed in the JZT profile within S1S3 have been merged into one dominant peak in YB. Again, variations in ARM almost duplicate those in $\chi$.

\subsection{The $\chi / \chi_{\text {ARM }}$ Without the Background Correction}

[27] Experiments on synthetic samples (Figure 3) clearly illustrate that $\chi / \chi$ ARM steadily decreases with decreasing grain sizes above $\sim 70 \mathrm{~nm}$. However, with further decreasing grain sizes from $70 \mathrm{~nm}$ to $16 \mathrm{~nm}, \chi_{/} \chi_{\text {ARM }}$ slightly increases from $\sim 0.07$ to $\sim 0.1$. Below $16 \mathrm{~nm}, \chi^{/} \chi_{\text {ARM }}$ sharply increases up to $\sim 1.8$ for $12 \mathrm{~nm}$ particles. So far, data for particles less than $12 \mathrm{~nm}$ is unavailable. However, we can reasonably assume that there are decreasing trends for both ARM and $\chi$ when grain size is less than $12 \mathrm{~nm}$ (dashed lines in Figures $3 \mathrm{c}$ and $3 \mathrm{~d}$ ), corresponding to SP grains.

[28] If we further assume a uniform grain-size distribution of the pedogenic particles between 0 and $70 \mathrm{~nm}$, then the average $\chi / \chi_{\text {ARM }}$ is $\langle\chi\rangle /\left\langle\chi_{\text {ARM }}\right\rangle$, where $\langle\chi\rangle(570.4 \times$ $10^{-6} \mathrm{~m}^{3} \mathrm{~kg}^{-1}$, in Figure $\left.3 \mathrm{c}\right)$ and $\left\langle\chi_{\mathrm{ARM}}\right\rangle(582.2 \times$ $10^{-5} \mathrm{~m}^{3} \mathrm{~kg}^{-1}$, in Figure $3 \mathrm{~d}$ ) represent the average values of $\chi$ and $\chi_{A R M}$ between 0 and $70 \mathrm{~nm}$, respectively. Then the average $\chi / \chi_{\text {ARM }}$ for this size range is $\sim 0.1$.

[29] The $\chi / \chi_{\text {ARM }}$ ratios against depth and against $\chi$ for these three profiles are summarized in Figures 2 and 4, respectively. For the JZT loess samples, the susceptibility values are limited around $2.6 \times 10^{-7} \mathrm{~m}^{3} \mathrm{~kg}^{-1}$, consistent with the previously obtained average loess susceptibility $\sim 2.8 \times 10^{-7} \mathrm{~m}^{3} \mathrm{~kg}^{-1}$ by Maher and Thompson [1995], but the corresponding $X^{\prime} / \chi_{\text {ARM }}$ ratios vary between $\sim 0.25$ and 0.4 . However, Figure 2 shows that the samples with "loesslike" susceptibility near the loess/paleosol transitions, referred as to zone II (Figure 2), have lower $\chi / \chi_{\text {ARM }}$ values compared to the pristine loess samples of zone I with minor pedogenic alterations. Even though samples of both type I and II have $\chi$ values of $\sim 2.6-3.0 \mathrm{~m}^{3} \mathrm{~kg}^{-1}$, the type I samples have higher $\chi / \chi_{\text {ARM }}$ ratios of $\sim 0.37-0.42$ than the type II samples with $\chi / \chi_{\text {ARM }}$ values between $\sim 0.27$ and 0.37 . The average $\chi / \chi_{A R M}$ of the type I samples (in Figure 2) is $0.378 \pm 0.027$.

[30] With increasing susceptibility, $\chi / \chi_{A R M}$ ratios gradually decrease (Figure 4) along almost the same trend for both JZT and YC samples (type III). When $\chi$ approaches $12.6 \times$ $10^{-7} \mathrm{~m}^{3} \mathrm{~kg}^{-1}, \chi / \chi_{\text {ARM }}$ reaches its lowest limit, about $\sim 0.130-0.170$. Further increase of susceptibility does not apparently affect $\chi / \chi_{A R M}$, indicating that the grain-size distribution remains almost stable despite the steady increase in the concentration of the $\chi$ and ARM carriers (type IV).

[31] Samples spanning the boundaries of L1/S1 and $\mathrm{S} 1 / \mathrm{L} 2$ for the YC section are referred to as type V due to their special properties, with $\chi$ resembling that of type III and $\chi / \chi_{\text {ARM }}$ resembling that of type IV, respectively.

\section{3. $\Delta \chi / \chi_{\text {ARm }}\left(\chi / \chi_{\text {arm }}\right.$ After the Background Correction)}

[32] For a bulk sample, susceptibility $\chi$ can be expressed as

$$
\chi_{\mathrm{B}}=\chi_{\text {para }}+\chi_{\mathrm{SP}}+\chi_{>\mathrm{SP}},
$$

where $\chi_{B}$ is the bulk susceptibility and $\chi_{\text {para }}, \chi_{S P}$, and $\chi_{>S P}$ are respectively the portion of susceptibility carried by the paramagnetic background (generally by silicates), by superparamagnetic grains, and by ferrimagnetic grains coarser than SP grains (SD + PSD + MD). $\chi_{\text {para }}$ is usually obtained from the high-field slope of the hysteresis loop [Hunt et al., 1995; Evans and Heller, 2003]. After removing $\chi_{\text {para }}$, the residual susceptibility is named $\chi_{\text {ferri }}$ :

$$
\chi_{\text {ferri }}=x-\chi_{\text {para }}=\chi_{\mathrm{SP}}+\chi_{>\mathrm{SP}}
$$

Clearly, $\chi_{\text {ferri }}$ consists of two parts, $\chi_{S P}$ and $\chi_{>S P}$, where the carrier of $\chi_{S P}$ theoretically does not carry remanences. Therefore SP grains in loess samples may lead to overestimates of grain size based on the ratio $\chi_{\text {ferri }} / \chi_{\text {ARM }}$.

[33] Figure 5 shows that there are strong linear correlations $\left(R^{2}>0.95\right)$ between $\chi$ and ARM for these three profiles. These strong linear trends suggest a simple mixing of two components: a constant primary aeolian component, with varying amounts of pedogenically added fine grains. The slopes can thus be associated with the grain size of the pedogenic fraction, while the intercept is more closely related to the aeolian fraction. The intercept susceptibility $\left(\chi_{0}\right)$ is $1.505 \times 10^{-7} \mathrm{~m}^{3} \mathrm{~kg}^{-1}$ (for JZT), $1.585 \times$ $10^{-7} \mathrm{~m}^{3} \mathrm{~kg}^{-1}$ (for YB), and $1.898 \times 10^{-7} \mathrm{~m}^{3} \mathrm{~kg}^{-1}$ (for $\mathrm{YC})$. It is noted that $\chi_{0}$ includes both paramagnetic $\left(\chi_{\text {para }}\right)$ and nonpedogenic MD ferrimagnetic components but not SP components because the point $\left(\chi_{0}, 0\right)$ is related to an ideal initial aeolian state without pedogenic effects. A detailed physical interpretation of $\chi_{0}$ is presented in the 

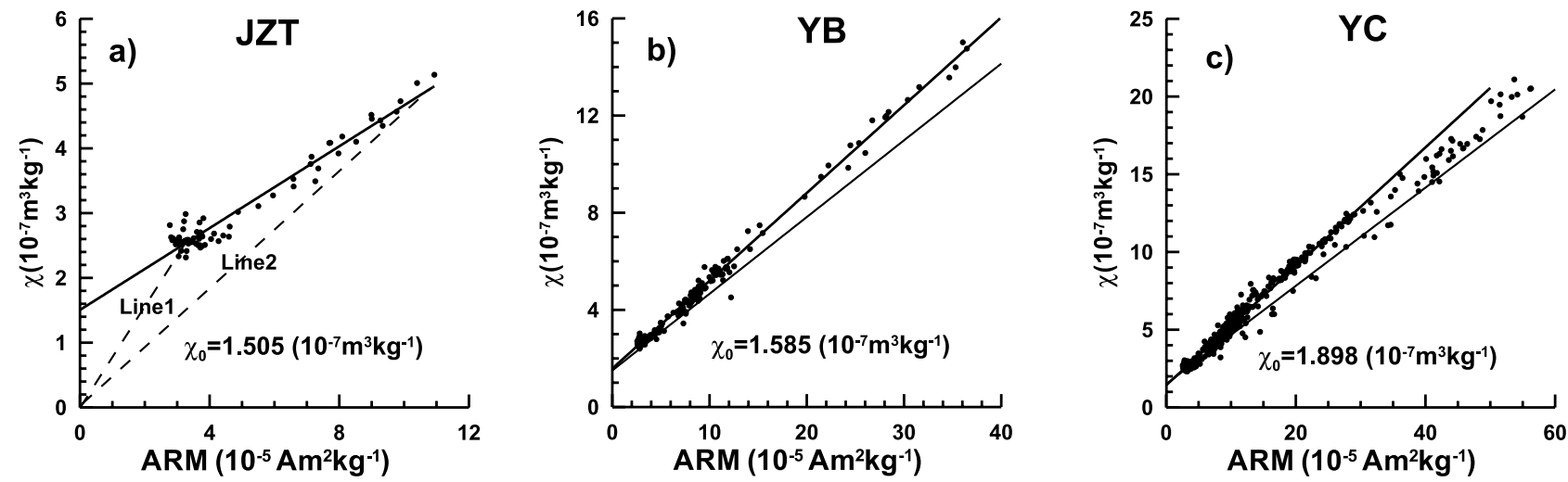

Figure 5. Plots of $\chi$ against ARM for the (a) JZT, (b) YB, and (c) YC sections. The thick lines are fitted linear trends; $\chi_{0}$ is the extrapolated susceptibility when ARM is zero. The estimated $\chi_{0}$ for JZT, YB, and $\mathrm{YC}$ are $1.505,1.585$, and $1.89810^{-7} \mathrm{~m}^{3} \mathrm{~kg}^{-1}$, respectively. The dashed lines (line 1 and line 2 ) in Figure 5a clearly show that the slope systematically decreases from the line 1 to line 2 when $\chi$ and ARM

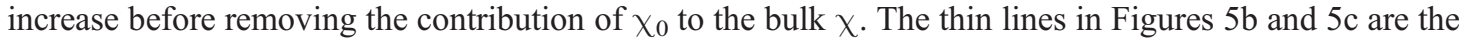
trend obtained in Figure 5a.

discussion section 5.3. The consistency of $\chi_{0}$ between the JZT, YB and YC sections strongly indicates that the initial aeolian material for three two less altered sites are almost identical. The higher $\chi_{0}$ for the YC section may indicate differences in the initial aeolian input.

[34] The depth plots of background-corrected $\chi / \chi_{\text {ARM }}$ $\left(\Delta \chi / \chi_{\text {ARM }}\right.$, where $\Delta \chi$ is $\left.\chi-\chi_{0}\right)$ for these three profiles are summarized in Figure 6. Apparently, the data are different from Figure 2, not only in absolute values but also in the patterns of spatial variations in the ratios, which have dramatically changed.

[35] Figure 7 shows the plots of $\Delta \chi / \chi_{\text {ARM }}$ versus $\Delta \chi$. In zone I for the less altered loess units, $\Delta \chi / \chi_{\text {ARM }}$ is between $\sim 0.145$ and 0.22 , about $50 \%$ lower than the uncorrected $\chi / \chi_{\text {ARM. }}$ In the transition zone II from the loess to paleosol units, $\chi$ does not apparently change, but the lowest $\Delta \chi$ / $\chi_{\text {ARM }}$ could decrease to $\sim 0.09$. In zone III (intermediate paleosol), there is a positive correlation between $\Delta \chi / \chi_{\text {ARM }}$ and $\Delta x$, instead of the clearly negative correlation seen in Figure 4 . In the mature paleosol zone IV, $\Delta \chi_{X} / \chi_{\text {ARM }}$ is statistically independent of the variations in $\Delta x$. The corresponding average $\Delta \chi^{/} \chi_{\text {ARM }}$ is $\sim 0.165$ (Figure $7 d$ ).

4.4. Frequency-Dependent Susceptibility $\chi_{\mathbf{f d}} \%$ and $\chi_{\mathrm{fd}}$ [36] The frequency-dependent susceptibility $\chi_{\mathrm{fd}} \%$ and its relationships with ARM, $\chi$, and $\Delta x$ are shown in Figure 8. On the basis of previous studies, the theoretical maximum $\chi_{\mathrm{fd}} \%$ for broad size distributions agrees with the maximum

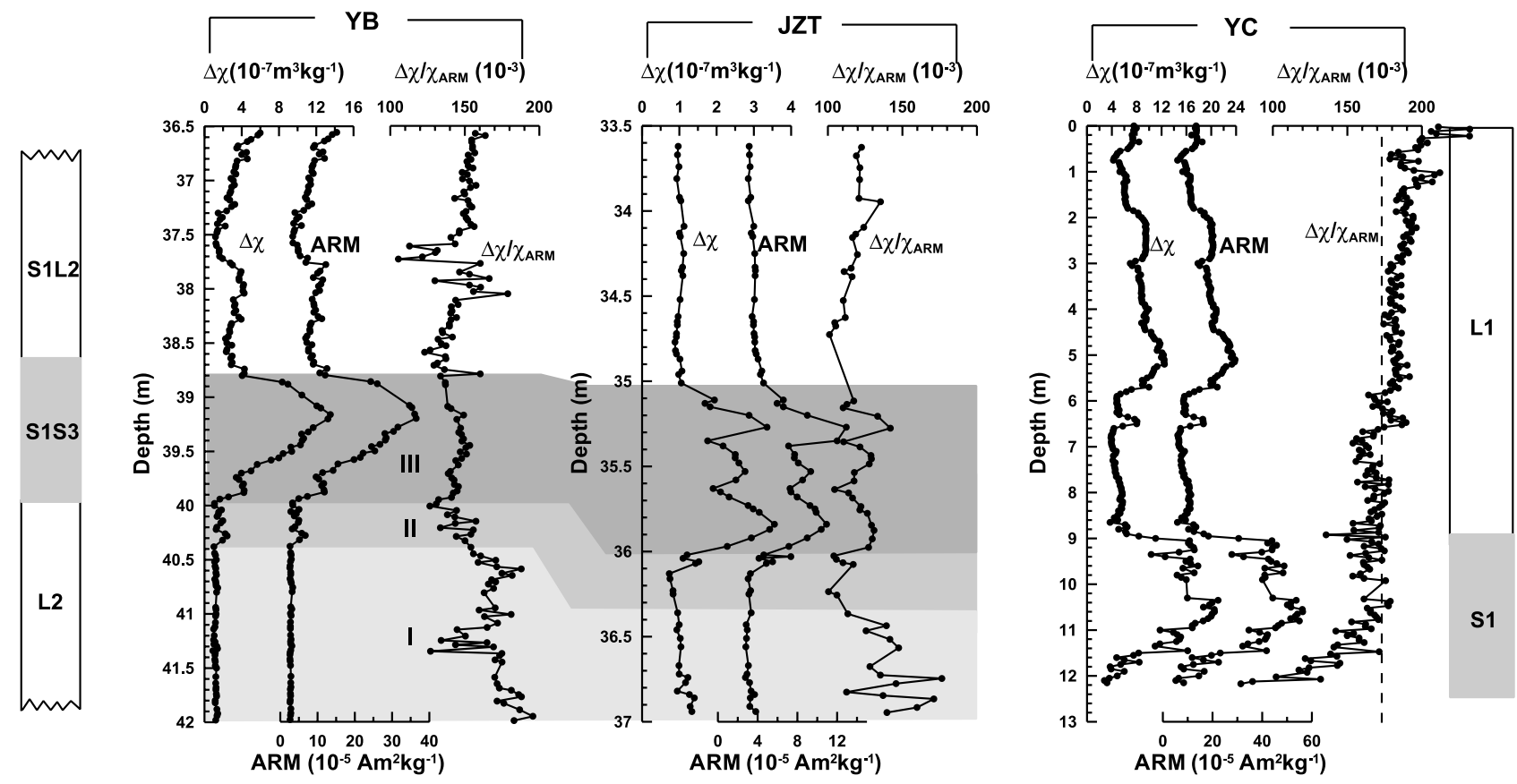

Figure 6. Stratigraphy, $\Delta \chi, A R M$, and $\Delta \chi_{\chi} / \chi_{\text {ARM }}$ of YB, YC, and JZT. I, II, and III represent three distinct zones. 

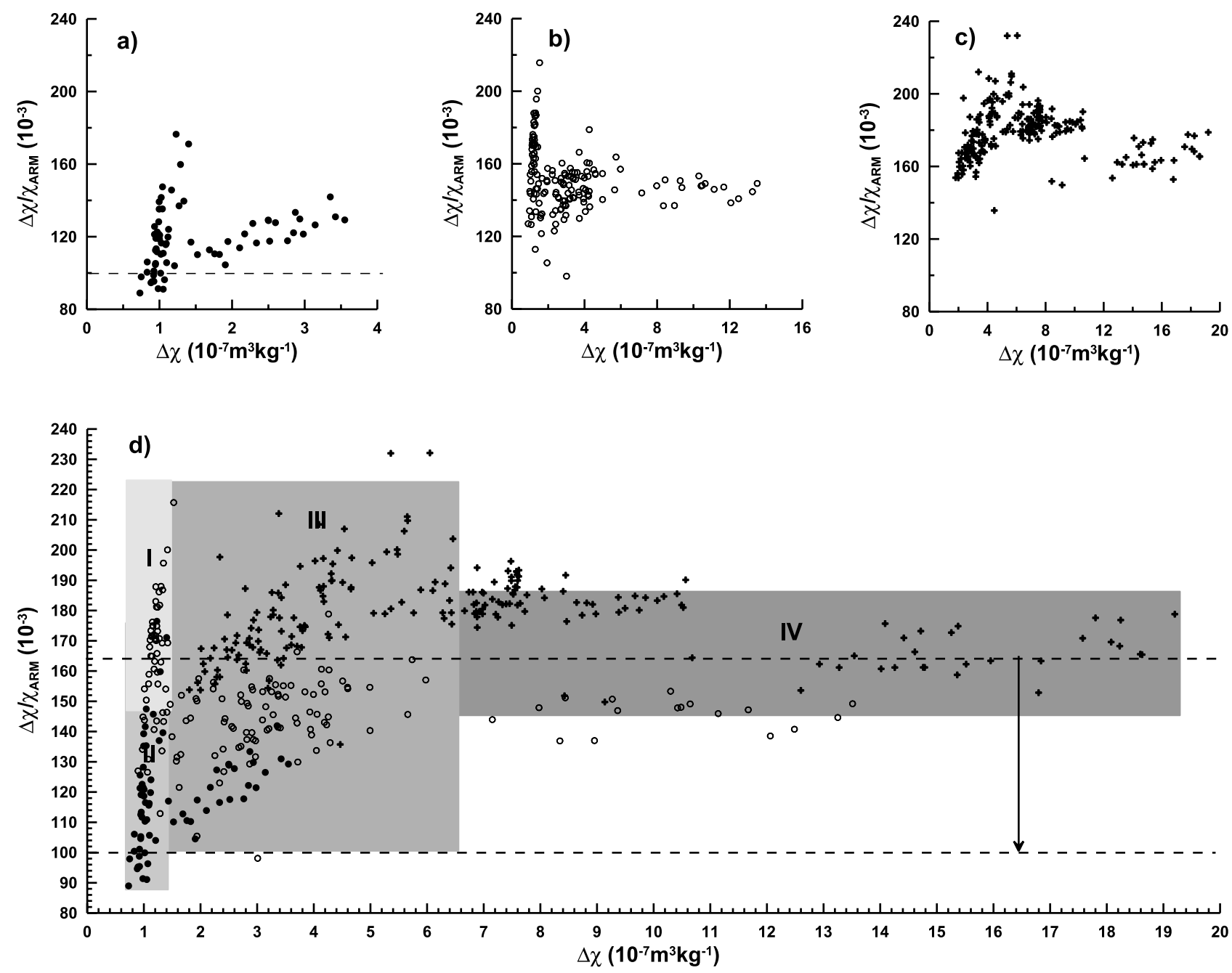

Figure 7. Plots of $\Delta \chi / \chi_{\text {ARM }}$ against $\Delta \chi$ for (a) JZT, (b) YB, and (c) YC. (d) All of these three profiles in Figures $7 \mathrm{a}, 7 \mathrm{~b}$, and $7 \mathrm{c}$. The two horizontal dashed lines correspond to the average $\Delta \chi / \chi_{\text {ARM }}$ for the mature paleosol samples $(\sim 0.165)$ in zone IV and synthetic samples $(\sim 0.095)$ between 16 and $100 \mathrm{~nm}$. In Figure 7d, notations of I, II, III, and IV are consistent with Figure 3.

observed in environmental samples (e.g., soils and loess), e.g., 8-15\% [Stephenson, 1971; Mullins and Tite, 1973; Mullins, 1977; Dearing et al., 1996; Oldfield et al., 1985; Hunt, 1986; Forster et al., 1994; Chen et al., 1999]. $\chi_{\mathrm{fd}} \%$ can be much higher for narrower size distributions [Worm, 1998; Worm and Jackson, 1999], but these are not encountered in loess or paleosols. Worm [1998] proposed that the limited $\chi_{\mathrm{fd}} \%<15 \%$ is probably caused by effects of a bimodal distribution or the coexistence of SP and SD particles with their ratio less than a certain value.

[37] On the basis of theoretical calculations, Dearing et al. [1996] predicted a maximum $\chi_{\mathrm{fd}} \%$ of $14-17 \%$ for spherical SP ferrimagnetic grains in the grain-size range $10-25 \mathrm{~nm}$, and a maximum value of $10-12 \%$ for grain assemblages spanning a wider range of grain sizes $(0-$ $30 \mathrm{~nm}$ ). Further synthetic and experimental data support the model predictions in terms of both maximum $\chi_{\mathrm{fd}} \%$ values and the relationship between $\chi_{\mathrm{fd}} \%$ and mass-specific $\chi$, which exhibits an envelope of data points partly related to grain-size distributions within the SP range. When $\chi_{\mathrm{fd}} \%$ is at a maximum, the mass specific $\chi_{\mathrm{fd}}$ can be used to estimate the concentration of SP grains in a sample [Dearing et al., 1996]. Then we expect a linear relationship between $\chi_{\mathrm{fd}}$ and the low-frequency $\chi\left(\chi_{L F}\right)$ caused solely by these extremely finer-grained particles, namely, $\chi_{\text {SP }}=\alpha \times \chi_{f d}$, where $\alpha$ is a constant.

[38] We estimate this constant theoretically based on the model by Dearing et al. [1996], in which the susceptibility ratio of SP and SD grains can be expressed as $\ln \left(f_{0} / F\right)$, where $f_{0}$ is on the order of $10^{9} \mathrm{~s}^{-1}$, and $F$ is the frequency used for the susceptibility measurements. Therefore the maximum SP value of $\chi_{\mathrm{LF}}(F=930 \mathrm{~Hz}$ for Kappa Bridge) is 13.88 times the $\mathrm{SD}$ value and $\chi_{\mathrm{fd}}$ should not exceed $\ln (4000 \mathrm{~Hz} / 400 \mathrm{~Hz}) \approx 2.3 \times \chi_{\mathrm{SD}}$. Because the $\chi_{\mathrm{LF}}$ and $\chi_{\mathrm{fd}}$ against grain-size curves have an approximately triangular form (e.g., Figure 3c), a uniform distribution of SP particles between 0 and $30 \mathrm{~nm}$ will have respective values for $\chi_{L F}$ and $\chi_{\mathrm{fd}}$ of about $6.94 \times \chi_{\mathrm{SD}}$ and $1.15 \times \chi_{\mathrm{SD}}$ (roughly half of the maximum), and thus $\chi_{\mathrm{sP}}=6.94 / 1.15^{*} \chi_{\mathrm{fd}} \approx 6.0^{*} \chi_{\mathrm{fd}}$. For example, if a sample has $\chi_{\mathrm{fd}}=1 \times 10^{-7} \mathrm{~m}^{3} \mathrm{~kg}^{-1}$, then SP grains in samples contribute $6 \times 10^{-7} \mathrm{~m}^{3} \mathrm{~kg}^{-1}$ to the bulk susceptibility. 

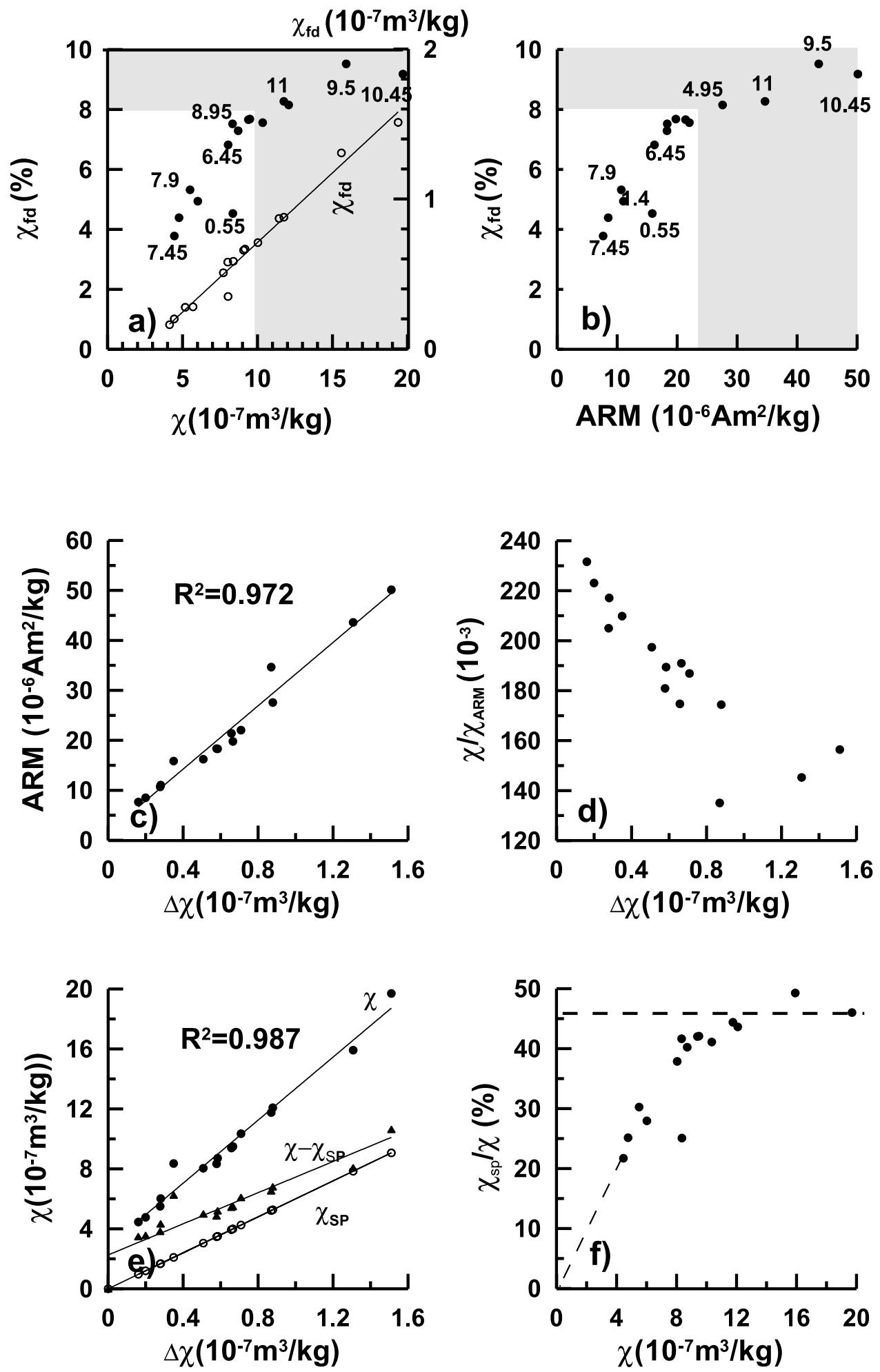

Figure 8. Rock magnetic results for characteristic samples from YC. (a) and (b) Frequency-dependent susceptibility $\chi_{\mathrm{fd}} \%$ (solid circle) and $\chi_{\mathrm{fd}}$ (open circle) against $\chi$ and ARM, respectively. These parameters are sensitive to the SP grains of $\sim 20 \mathrm{~nm}$ [Stephenson, 1971]. The $R^{2}$ of the linear trend between $\chi_{\mathrm{fd}}$ and $\chi$ is 0.98. Numbers in Figures 8a and $8 \mathrm{~b}$ are depths. (c) and (d) ARM and $\chi / \chi_{\text {ARM }}$ against $\Delta \chi$, respectively. Line in Figure $8 \mathrm{c}$ is the linear trend with $R^{2}$ of 0.97 . (e) Bulk susceptibility $\chi$ (solid circle), $\chi_{s p}$ (open circle), and $\chi-\chi_{s p}$ (solid triangle) against $\Delta \chi$. (f) Percentage $\chi_{s p} / \chi$ against $\chi$. The dashed line shows that about $45 \%$ is the maximum contribution of $\chi_{\mathrm{sp}}$ to the bulk $\chi$. 

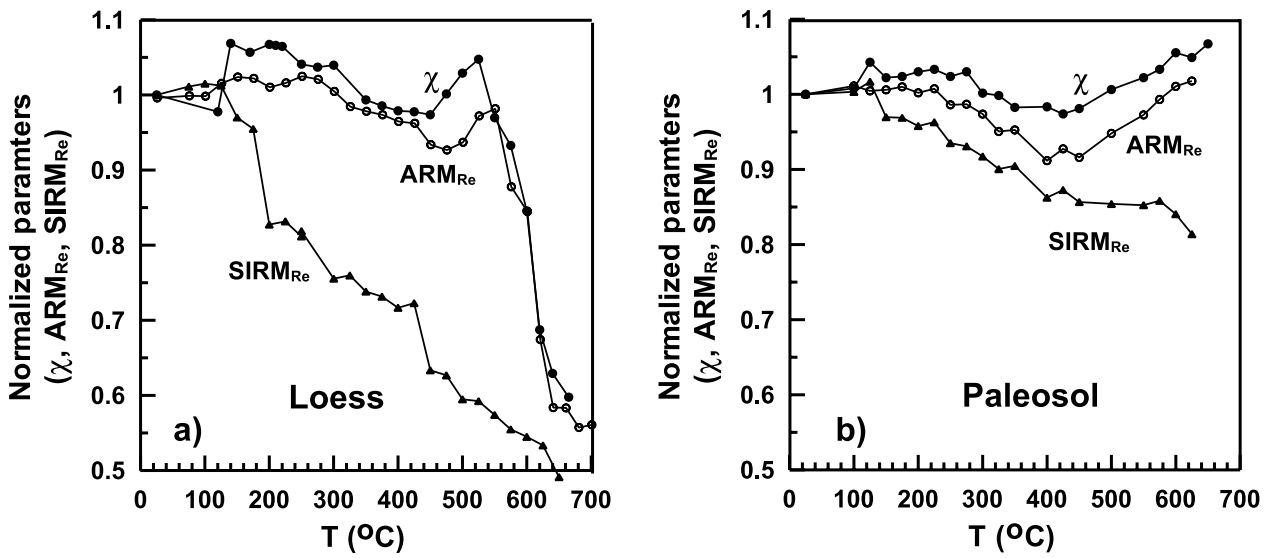

Figure 9. Thermal behavior of $\chi, A_{R} M_{R e}$ and $S_{I R M}$ for (a) the loess sample at $34.45 \mathrm{~m}$ from the JZT section and (b) a paleosol sample at $10.55 \mathrm{~m}$ from the YC section. Temperatures are the maximum temperatures of different thermal runs.

[39] Figure 8a shows that $\chi_{\mathrm{fd}} \%$ and $\chi$ are positively correlated, but not linearly. For the mature paleosol S1 with $\chi$ larger than $8 \times 10^{-7} \mathrm{~m}^{3} \mathrm{~kg}^{-1}, \chi_{\mathrm{fd}} \%$ is almost susceptibility independent. It seems that $8-10 \%$ is the maximum that $\chi_{\mathrm{fd}} \%$ can reach for this profile. However, there is a strong and positive linear correlation between $\chi$ and $\chi_{\mathrm{fd}}$ $\left(R^{2}=0.98\right)$. The relationship between $\chi_{\mathrm{fd}} \%$ and ARM is

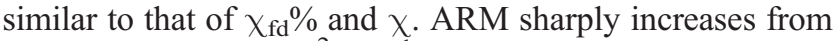
$\sim 200$ to $\sim 380 \mu \mathrm{A} \mathrm{m} \mathrm{kg}^{-1}$, while $\chi_{\mathrm{fd}} \%$ remains almost unchanged between 8 and $10 \%$ (Figure $8 \mathrm{~b}$ ).

[40] In contrast, the absolute $\chi_{\mathrm{fd}}$ values and ARM are linearly correlated $\left(\mathrm{R}^{2}=0.97\right)$ throughout, indicating that the concentration of both SP and SD grains steadily increases with increasing pedogenesis. The maximum $\chi_{\mathrm{fd}}$ is about $1.5 \times 10^{-7} \mathrm{~m}^{3} \mathrm{~kg}^{-1}$, and the corresponding estimate of $\chi_{\mathrm{SP}}$ is $9.0 \times 10^{-7} \mathrm{~m}^{3} \mathrm{~kg}^{-1}$. Figure 8 estimates the relative percentage of $\chi_{\mathrm{SP}} / \chi$. When $\chi$ is larger than about $12.0 \times$ $10^{-7} \mathrm{~m}^{3} \mathrm{~kg}^{-1}$ (mature paleosol), $\chi_{\mathrm{sp}} / \chi$ reaches its maximum $\sim 45-50 \%$. This strongly indicates that the concentration of SP grains steadily increases with increasing pedogenesis, and the maximum contribution to the bulk $\chi$ is about $\sim 45-50 \%$. However, this value is dependent on the constant $(\alpha=6.0)$ derived from Dearing et al.'s [1996] model. If we set the constant $\alpha$ to 3.0, then the ratio of $\chi_{\mathrm{SP}} / \chi$ is only $22.25-25 \%$, and it is SD grains instead of SP grains that dominate the magnetic enhancements.

\subsection{Thermal Alteration Spectra of $\chi, \mathbf{A R M}_{\mathrm{Re}}$, and $\operatorname{SIRM}_{\mathrm{Re}}$}

[41] The thermal behavior of $\chi$ and the concentration proxies after heating, $\mathrm{ARM}_{\mathrm{Re}}$ and $\mathrm{SIRM}_{\mathrm{Re}}$ are summarized in Figure 9. For the loess sample, susceptibility apparently increases around $150^{\circ} \mathrm{C}$. On the whole, both susceptibility and $\mathrm{ARM}_{\mathrm{Re}}$ remain stable below $\sim 550^{\circ} \mathrm{C}$. Then sharp drops of $\sim(40-45) \%$ occur for these two parameters above $\sim 550^{\circ} \mathrm{C}$. Unlike $\chi$ and $\mathrm{ARM}_{\mathrm{Re}}, \mathrm{SIRM}_{\mathrm{Re}}$ dramatically starts to drop around $(175-200)^{\circ} \mathrm{C}$, then decreases almost linearly at higher temperatures. For the mature paleosol sample, $\chi$ and $\mathrm{ARM}_{\mathrm{Re}}$ share most of thermal features shown by the loess sample below $550^{\circ} \mathrm{C}$. However, above $550^{\circ} \mathrm{C}$, both $\chi$ and $\mathrm{ARM}_{\mathrm{Re}}$ steadily increase without sharp drops. The paleosol SIRM $\mathrm{Se}_{\mathrm{Re}}$ shows a pattern similar to that of the loess samples except for smaller loss in remanences $(<20 \%)$ after a $(600-700)^{\circ} \mathrm{C}$ run. Even though the behavior of the loess and paleosol samples are very different, for each sample the thermal behavior of $\mathrm{ARM}_{\mathrm{Re}}$ and $\chi$ are consistent. In contrast, for both the loess and paleosol, SIRM carriers are very different from the $\chi$ and ARM carriers.

[42] Figure 10a shows variations in $\chi_{/} \chi_{\text {ARM }}$ for different thermal products. The initial $\chi / \chi_{\text {ARM }}$ for the loess and paleosol sample are $\sim 0.33$ and $\sim 0.144$, respectively. With increasing heating temperature $T_{\text {tr }}$, the $\chi_{/} / \chi_{\text {ARM }}$ ratios slightly increase to a maximum of $\sim 0.360$ at $500^{\circ} \mathrm{C}$ for the loess, and $\sim 0.154$ at $\sim 400^{\circ} \mathrm{C}$ for the paleosol, respectively. Then $\chi / \chi_{\text {ARM }}$ ratios decrease with further increase of $T_{\text {tr }}$. Figure $10 \mathrm{~b}$ illustrates a clear negative correlation between $\chi / \chi_{\text {ARM }}$ and ARM (normalized). A notable feature for the loess sample is that $\chi / \chi_{\text {ARM }}$ increases with a lower rate (light dashed line) with decreasing ARM when $T_{\text {tr }}$ is higher than $550^{\circ} \mathrm{C}$ compared to the general trend (thick dashed line in Figure 10).

\subsection{Magnetic Extract Efficiencies and Separation Properties}

[43] Table 1 lists the magnetic properties of two representative bulk samples and residues after extraction. The magnetic properties of the paleosol sample are significantly enhanced, as revealed by $\lambda_{P} / \lambda_{L}$ (where $\lambda_{P}$ and $\lambda_{L}$ are the properties of the paleosol and the loess sample and $\lambda$ is one of the following parameters, $M_{s}, M_{\mathrm{rs}}$, ARM, and $\chi$ ), but with different degrees of enhancement.

[44] Among these parameters, $M_{S}$ is grain-size-independent and serves as the concentration proxy, indicating that paleosol $\left(M_{s} \sim 8.54 \times 10^{-2} \mathrm{~A} \mathrm{~m}^{2} \mathrm{~kg}^{-1}\right)$ contains 2.62 times as much ferrimagnetic material as the loess $\left(M_{s} \sim 3.254 \times\right.$ $\left.10^{-2} \mathrm{~A} \mathrm{~m}^{2} \mathrm{~kg}^{-1}\right) . M_{\mathrm{rs}}$, ARM and $\chi$ are controlled by both concentration and grain-size distribution of the magnetic material. ARM and $\chi$ for the paleosol sample are enhanced 6.80 and 4.85 times, respectively, suggesting that more SD material is produced by pedogenesis than SP material.

\section{Discussion}

\subsection{Selection of Magnetic Ratio $\chi / \chi_{\text {ARM }}$ or $\chi / S I R M$}

[45] For the Chinese loess/paleosol sequences, ARM and SIRM are carried mainly by strongly ferrimagnetic minerals 

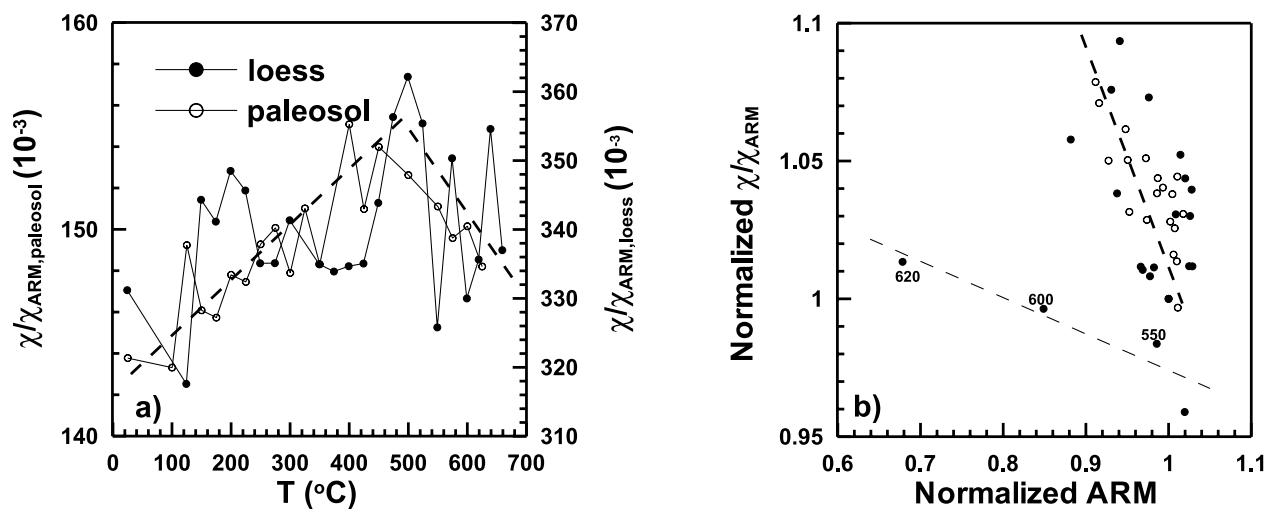

Figure 10. Temperature (treated) dependent behavior of $\chi / \chi_{\text {ARM }}$ for the selected loess and paleosol samples (same in Figure 9). Dashed lines indicate the corresponding linear trends. Numbers in Figure 10b are the treatment temperatures.

(magnetite/maghemite); therefore values of $\mathrm{ARM}_{\mathrm{Re}}$ and SIRM $_{R e}$ reflect primarily the concentrations of ferrimagnetic carriers of different thermal products and changes due to heating. During the thermal treatments, these ferrimagnetic minerals undergo mainly two kinds of alterations. The first is the isochemical phase transformation, e.g., from strongly magnetic but metastable maghemite $\left(\gamma \mathrm{Fe}_{2} \mathrm{O}_{3}\right)$ to weakly magnetic hematite $\left(\alpha \mathrm{Fe}_{2} \mathrm{O}_{3}\right)$ resulting in a sharp loss in remanence intensities. The second sort of alteration involves oxidation/reduction. In contrast to the abrupt changes often associated with mineral transformations, chemical alteration tends to result in relatively continuous and lower amplitude fluctuations in magnetic parameters.

[46] The detection of reduction and oxidation of the loess sample during heating is complex. However, for our purpose, it is not necessary to clearly determine the exact alteration processes. Because the finer-grained magnetite particles in the Chinese loess/paleosols have been extensively oxidized into maghemite [Maher and Thompson, 1991, 1992], we simplify the loess mineralogy: the finergrained (SD/SP) magnetic particles are maghemite, and the coarser-grained (coarser PSD and MD) magnetic particles are partially oxidized magnetite. If two parameters are carried by identical carriers, they must have consistent thermal behaviors. Otherwise, we can distinguish them based on characteristic mineral transformations that occur during heating.

[47] Figure 9 shows that susceptibility and $\mathrm{ARM}_{\mathrm{Re}}$ for the loess sample (the concentration proxy of ARM carriers) exhibit almost identical thermal patterns, relatively stable below $\sim 550^{\circ} \mathrm{C}$ and sharply dropping by $\sim 45 \%$ at higher temperatures, where maghemite is inverted to hematite. These maghemite particles presumably have finer grain sizes and have been fully oxidized to maghemites due to their higher surface/volume ratios. In contrast, the gradual decrease of SIRM $_{\mathrm{Re}}$ with increasing $T_{\mathrm{tr}}$ is most probably caused by the oxidation from magnetite to maghemite + hematite.

[48] The magnetic carriers of the loess $\chi$ and ARM are different from those in the paleosols, but in each sediment type (loess or paleosol), $\chi$ and ARM are carried by a more common population of grains than $\chi$ and SIRM. Consequently, the $\chi / \chi_{A R M}$ ratio is a more reliable grain-size indicator than $\chi / S I R M$ or ARM/SIRM. However, we have to note that $\chi$ and $\chi_{A R M}$ reflect a weighted average response of all magnetic particles in samples. For example, the SP grains contribute strongly to $\chi$, but nothing to ARM, which is acquired very efficiently by SD grains Further, both MD and PSD grains also carry ARM and $\chi$. Nevertheless, the almost identical thermal spectra of $\chi$ and $\mathrm{ARM}_{\mathrm{Re}}$ strongly indicate that these two parameters share the same dominant sources.

[49] However, the consistency of the thermal alteration behavior among $\chi$ and $\mathrm{ARM}_{\mathrm{Re}}$ still does not guarantee that they are dominated by grains with narrow size distributions. For example, the variations in the thermal behavior (Figures 9a and 9b) could be superimposed on a stable background carried by very different magnetic sources. Therefore further constraints arise from the magnetic extract efficiencies (EE) (Table 1).

Table 1. Magnetic Properties and the Corresponding Extract Efficiencies for the Loess (40.02 m), Paleosol (39.20 m), and the Residues From the YB Section

\begin{tabular}{|c|c|c|c|c|c|c|c|}
\hline & Loess & Loess Res & Loess EE, \% & Paleosol & Paleosol Res & Paleosol EE, \% & $\lambda_{\mathrm{P}} / \lambda_{\mathrm{L}}{ }^{\mathrm{a}}$ \\
\hline$M_{s}, 10^{-2} \mathrm{~A} \mathrm{~m}^{2} \mathrm{~kg}^{-1}$ & 3.254 & 0.284 & 91.3 & 8.540 & 3.546 & 58.5 & 2.62 \\
\hline$M_{\mathrm{rs}}, 10^{-3} \mathrm{~A} \mathrm{~m}^{2} \mathrm{~kg}^{-1}$ & 4.446 & 0.505 & 88.7 & 15.030 & 6.996 & 53.5 & 3.38 \\
\hline ARM, $10^{-5} \mathrm{~A} \mathrm{~m}^{2} \mathrm{~kg}^{-1}$ & 3.930 & 1.383 & 64.8 & 36.465 & 26.729 & 26.7 & 6.80 \\
\hline $\mathrm{x}, 10^{-7} \mathrm{~m}^{3} \mathrm{~kg}^{-1}$ & 2.715 & 0.353 & 87.0 & 13.175 & 11.568 & 12.2 & 4.85 \\
\hline$\chi / M_{\mathrm{s}}, 10^{-6} \mathrm{~m} \mathrm{~A}^{-1}$ & 8.34 & 12.43 & & 15.43 & 32.62 & & \\
\hline$B_{c}, \mathrm{mT}$ & 15.1 & 38.2 & & 8.99 & 7.26 & & \\
\hline$B_{\mathrm{cr}}, \mathrm{mT}$ & 48.4 & 170 & & 23 & 18.4 & & \\
\hline$B_{\mathrm{cr}} / B_{c}$ & 3.205 & 4.450 & & 2.534 & 2.558 & & \\
\hline$M_{\mathrm{rs}} / M_{S}$ & 0.137 & 0.187 & & 0.177 & 0.197 & & \\
\hline$\chi / \chi_{\text {ARM }}$ & 0.21 & 0.076 & & 0.108 & 0.129 & & \\
\hline
\end{tabular}

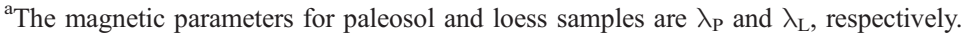


[50] EE is strongly affected by the grain-size distribution of the magnetic grains in samples. Generally, coarsergrained particles are more efficiently extracted than the finer-grained particles. The SP grains tend to remain in the residues. Generally, the $\chi$ and ARM can be expressed as

$$
\begin{gathered}
\chi_{\mathrm{B}}=\chi_{\mathrm{para}}+\chi_{\mathrm{SP}}+\chi_{\mathrm{SD}}+\chi_{\mathrm{PSD}}+\chi_{\mathrm{MD}} \\
\mathrm{ARM}_{\mathrm{B}}=\mathrm{ARM}_{\mathrm{SD}}+\mathrm{ARM}_{\mathrm{PSD}}+\mathrm{ARM}_{\mathrm{MD}},
\end{gathered}
$$

where $\chi_{B}$ and $\mathrm{ARM}_{\mathrm{B}}$ are the susceptibility and $\mathrm{ARM}$ of the bulk sample and $\chi_{\mathrm{SP}}$ and $\mathrm{ARM}_{\mathrm{SD}}$ and so on are the contributions of different grain size fractions (details are summarized in the notation section). Generally, PSD and MD grains are extractable, and SD grains may be partially extractable. However, the SP grains are almost nonextractable.

[51] The high EE (91.3\%) of $M_{s}$ indicates that almost all of the ferrimagnetic material has been extracted. The relatively high EE of $\chi$ indicates that the loess $\chi$ is carried by relatively coarse grained particles $(>\mathrm{SD})$ of aeolian origin. Compared to the loess EEs, the paleosol EEs are systematically lower, especially for $\chi$ and ARM (only $12.2 \%$ and $26.7 \%$ ), indicating that the paleosol $\chi$ and ARM are dominantly carried by nonextractable finer-grained particles. The much higher paleosol EEs of $M_{s}(58.5 \%)$ and $M_{\mathrm{rs}}(53.5 \%)$ point out that about half of the $M_{s}$ and $M_{\mathrm{rs}}$ is carried by extractable coarser-grained particles. For the loess sample, the EEs for $\chi, A R M$, and $M_{\mathrm{rs}}$ are all fairly high, indicating that they all controlled by coarser-grained particles $(>\mathrm{SD})$. However, by combining this information with the thermal behavior (Figure 9a), we still believe that $\chi$ and ARM have more consistent carriers than $M_{\mathrm{rs}}$ does.

\subsection{Changes in the $\chi$ and ARM Carriers With $T_{\text {tr }}$}

[52] Figure 10 clearly indicates that the variations in ARM due to the thermal treatments directly relate to the changes in effective grain sizes of the ARM carrier. The slight decrease of ARM (thick dashed line) is caused by the slight increase of effective grain size (increase of $\chi^{\prime}$ $\chi_{\mathrm{ARM}}$ ). We may deduce that the subtle changes in grain size are caused by changes in reducing/oxidizing environment of the bulk sample during heating. Previous studies suggested that the burning of organic matter below $300^{\circ} \mathrm{C}$ results in a reducing environment. Then the finer-grained particles in the presence of organic carbon may have been partially reduced especially on the surface. The maghemite core becomes relatively smaller causing an increase of ARM. However, when $T_{\text {tr }}$ is higher than $300^{\circ} \mathrm{C}$, the bulk sample will be in an oxidizing environment, and the previously reduced magnetite rim will be oxidized to maghemite again. The direct result is that ARM decreases and is restored to the original value. However, with further increase of $T_{\mathrm{tr}}$, the surface of maghemite particles will be inverted to hematite causing a new hematite rim/maghemite core interaction, and also slightly decreasing the size of the maghemite core, which will increase ARM again.

[53] For the relatively coarser maghemite grains, the fast inversion from maghemite to hematite significantly decreases its ARM (loess ARM). However, for the much finer grained maghemite $(\mathrm{SP} / \mathrm{SD})$, it seems that the inversion from maghemite to hematite is inhibited. The mechanism of inversion from maghemite to hematite for finer-grained maghemite is still controversial. Some X-ray work indicates that the finer-grained maghemites do convert rapidly to hematite [Gallagher et al., 1968], whereas some torque measurements indicate the opposite [Senno et al., 1967]. However, the degree of stoichiometry or impurity substitution may be important in determining the speed as well as temperature for conversion. Impurities, e.g., aluminum, stabilize the $\gamma-\mathrm{Fe}_{2} \mathrm{O}_{3}$ [Gallagher et al., 1968]. The maghemite particles of pedogenic origin are believed to have high concentrations of crystal imperfections due to incorporation of such impurities in solid solution during pedogenesis. Therefore we may infer that this high thermal stability of these finer-grained pedogenic maghemite particles in paleosols indicate impurities.

[54] On the basis of this interpretation, we may find that the peak around $500^{\circ} \mathrm{C}$ for the loess $\mathrm{ARM}_{\mathrm{Re}}$ (Figure 9a) is, in fact, balanced by two processes, increase of ARM by decreasing the maghemite core, and decrease of ARM by decreasing maghemite volume by inversion from maghemite to hematite.

[55] Figures 9 and 10 provide only partial information for mineral transformation during heating of the Chinese loess/ paleosol samples. Therefore more parameters, e.g., hysteretic parameters, and other nonmagnetic studies (XRD, SEM, and high-resolution transmission electron microscopy) may be necessary to provide a more comprehensive model. However, this consideration is beyond our current scope, and will be covered in our next study. We believe that the comparison of thermal behaviors of $\chi, \mathrm{ARM}_{\mathrm{Re}}$, and $S_{\text {IRM }}$ provide sufficient information.

\subsection{Mixing Model and Significance of $\chi_{0}$ and $\Delta \times / \chi_{A R M}$}

[56] The simple binary mixing model contains just two components, an aeolian end-member with fixed grain size and invariant concentration, and a pedogenic component with a constant grain size and varying concentration. Although an obvious oversimplification, this model does account for an overwhelming majority of the variance in the data (Figure 5), and therefore provides a satisfactory firstorder description of the data. Now we consider further the relationship of the model and the data, the significance of deviations between them, and possible second-order models to explain the deviations.

[57] The properties of the aeolian end-member $\left(\chi_{\text {aeolian, }}, \mathrm{ARM}_{\text {aeolian }}\right)$ are not directly determined by the measured $\chi$ and ARM data, but they may be represented by a point $P_{1}$ constrained to lie on the mixing line, with values less than or equal to the minimum measured (Figure 11). Pedogenic production of fine ferrimagnets increases both $\chi$ and ARM in linear proportion to the concentration of authigenic carriers, with a fixed ratio $\chi_{\text {pedogenic }} / \mathrm{ARM}_{\text {pedogenic }}$ corresponding to their characteristic grain size. Thus

$$
\begin{aligned}
\chi= & \chi_{\text {aeolian }}+\chi_{\text {pedogenic }} \\
= & \chi_{\text {aeolian }}+\mathrm{ARM}_{\text {pedogenic }}\left(\chi_{\text {pedogenic }} / \mathrm{ARM}_{\text {pedogenic }}\right) \\
= & \chi_{\text {aeolian }}+\left(\mathrm{ARM}-\mathrm{ARM}_{\text {aeolian }}\right)\left(\chi_{\text {pedogenic }} / \mathrm{ARM}_{\text {pedogenic }}\right) \\
= & \operatorname{ARM}\left(\chi_{\text {pedogenic }} / \mathrm{ARM}_{\text {pedogenic }}\right)+\chi_{\text {aeolian }} \\
& -\operatorname{ARM}{ }_{\text {aeolian }}\left(\chi_{\text {pedogenic }} / \mathrm{ARM}_{\text {pedogenic }}\right) \\
= & \operatorname{ARM}\left(\chi_{\text {pedogenic }} / \mathrm{ARM}_{\text {pedogenic }}\right)+\chi_{0} .
\end{aligned}
$$

Thus the $\chi$-ARM regression slopes are directly related to the characteristic pedogenic grain size, whereas the intercept 


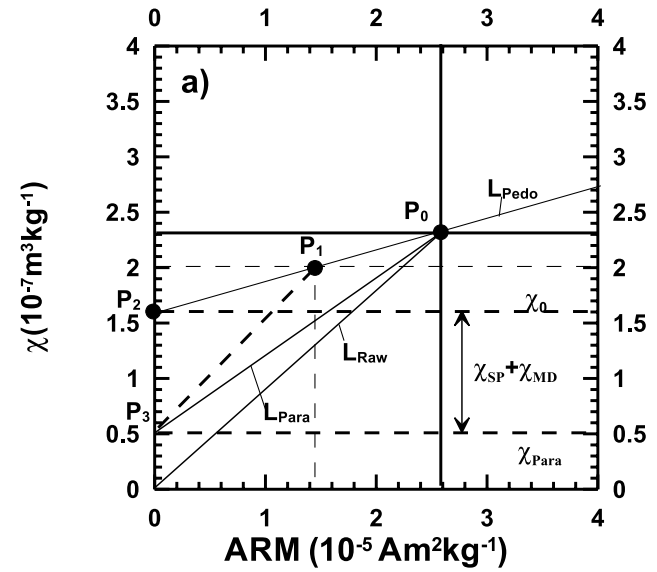

Figure 11. Conceptual model for the background susceptibility correction. $\mathrm{P}_{0}$ corresponds to the minimum susceptibility and ARM observed for these three profiles. $\mathrm{P}_{0}\left(\mathrm{ARM}_{\mathrm{Min}}, \chi_{\mathrm{Min}}\right)$ is the onset of pedogenesis. $\mathrm{P}_{1}$ $\left(\mathrm{ARM}_{\text {Unaltered }}, \chi_{\text {Unaltered }}\right)$ represent the pure aeolian endmember. $P_{2}$ is the extrapolated point $\left(0, \chi_{0}\right)$ where ARM is zero. $\mathrm{P}_{3}\left(0, \chi_{\text {para }}\right)$ represents the paramagnetic background. Generally, $\chi_{\text {para }}$ is about $0.5 \times 10^{-7} \mathrm{~m}^{3} \mathrm{~kg}^{-1}$. $\mathrm{L}_{\text {Pedo }}$ is the pedogenic trend obtained by least squares. $L_{\text {Raw }}$ is simply the ratio without any correction assuming that the measured bulk susceptibility is totally determined by $\chi_{>\text {SP. }} L_{\text {para }}$ is the trend after removing $\chi_{\text {para. }}$. The pedogenic trend is believed to be valid only to the point $\mathrm{P}_{1}$ $\left(\mathrm{ARM}_{\text {Unaltered, }} \chi_{\text {Unaltered }}\right)$. When $\chi$ is less than $\chi_{\text {Unaltered, }}$, the deduced trend is along $\mathrm{P}_{1}$ and $\mathrm{P}_{3}$ instead of $\mathrm{P}_{1}$ and $\mathrm{P}_{2}$.

$\chi_{0}$ has a more indirect physical significance. Nevertheless, since it is determined directly by the regression (Figure 5), we have used it as a first-order "background" correction for paramagnetic and aeolian ferrimagnetic components. Clearly, since $\chi_{0}<\chi_{\text {aeolian }}, \Delta \chi=\left(\chi-\chi_{0}\right)$ necessarily overestimates $\chi_{\text {pedogenic }}$. In taking the ratio $\Delta \chi / \chi_{\text {ARM }}$ as a corrected indicator of pedogenic grain size, the denominator is also slightly overestimated, since $\mathrm{ARM}_{\mathrm{B}}>\mathrm{ARM}$ pedogenic. Nevertheless, stratigraphic variations in the ratio $\Delta X_{X} / \chi_{A R M}$ (i.e., deviations from linearity in Figure 5) may therefore reasonably be attributed to small variations in pedogenic grain sizes.

[58] Before proceeding with an interpretation of pedogenic grain-size variation, however, we note that two other possible second-order variables may also be significant, namely aeolian grain size and concentration. Variations in the concentration of aeolian ferrimagnetic grains can be represented by the mixing line in Figure 12 between $\mathrm{P} 1$ and P3 (for which $\chi=\chi_{\text {paramagnetic }}$ and ARM $=0$ ). Because this mixing line has a steeper slope than $\chi_{\text {pedogenic }} / \mathrm{ARM}_{\text {pedogenic }}$ (related to the coarser average size of the detrital grains), higher or lower than average aeolian ferrimagnetic concentrations would be expected to result in higher or lower $\Delta \chi^{\prime}$ ARM ratios. Similarly, variations in aeolian ferrimagnetic grain size, and thus in $\left(\chi_{\text {aeolian }}, \mathrm{ARM}_{\text {aeolian }}\right)$, must also be reflected in $\Delta \chi / A R M$.

\subsection{Estimation of Grain Sizes of $\chi$ and ARM Carriers}

[59] Because the effects of SP grains for the loess samples in the least altered zone I are negligible, we can calibrate the grain sizes of the ARM and $\chi$ carriers by Figure $3 \mathrm{a}$. These samples (zone I) have the highest $\Delta \chi / \chi_{\text {ARM }}$ ratio $\sim 0.165-$ 0.24 , corresponding to $100-300 \mathrm{~nm}$. Because the correction of $\chi_{0}$ has efficiently removed much of the aeolian contribution from MD and coarser-grained PSD grains to the bulk $\chi$, unlike the Day plot, the grain-size estimation by $\Delta \chi^{\prime}$ $\chi_{A R M}$ is not the average size, but the lower limit.

[60] The estimation of the grain sizes of the ARM and $\chi$ carriers for the mature paleosol samples is characteristic of the pedogenic SP grains. The average $\Delta \chi / \chi_{\text {ARM }}$ for the paleosol samples is $\sim 0.16$, corresponding to an apparent mean grain size of $\sim 100 \mathrm{~nm}$ or alternatively $\sim 20 \mathrm{~nm}$ (Figure 3a).

[61] If we take 0.1 as the lowest $\chi / \chi_{\text {ARM }}$ for the synthetic samples with size less than $70 \mathrm{~nm}$ by Maher [1988], then we can estimate the contribution of the SP/viscous particles near the SP/SD boundary to the bulk susceptibility as $(0.16-0.1) / 0.16 \%=37.5 \%$.

\subsection{Origin of the $100-300 \mathrm{~nm}$ PSD Magnetic Grains in Loess}

[62] The grain sizes of the susceptibility and ARM carriers of the loess samples are not only uniform but also systematically higher than that of paleosols, strongly indicating that they originate from different mechanisms. Apparently, the SP/SD particles in paleosols are of pedogenic origin [Zhou et al., 1990; Maher and Thompson, 1991]. In contrast, the coarser magnetic grains with a wide grain-size distribution $(100-300 \mathrm{~nm})$ in the less altered loess units are independent of pedogenesis, and probably originate from aeolian sources or are produced by two-phase low-temperature oxidation. For detailed information about the low-temperature oxidation, refer to Cui et al. [1994] and Kosterov [2002]. With increasing pedogenesis the SP/SD grains gradually outweigh these initial coarser-grained particles in loess, resulting in a gradual increase of $\Delta \chi / \chi_{\text {ARM }}$ with increasing $\Delta \chi$. For the mature paleosols, these grains dominate, and $\Delta \chi^{\prime} \chi_{\text {ARM }}$

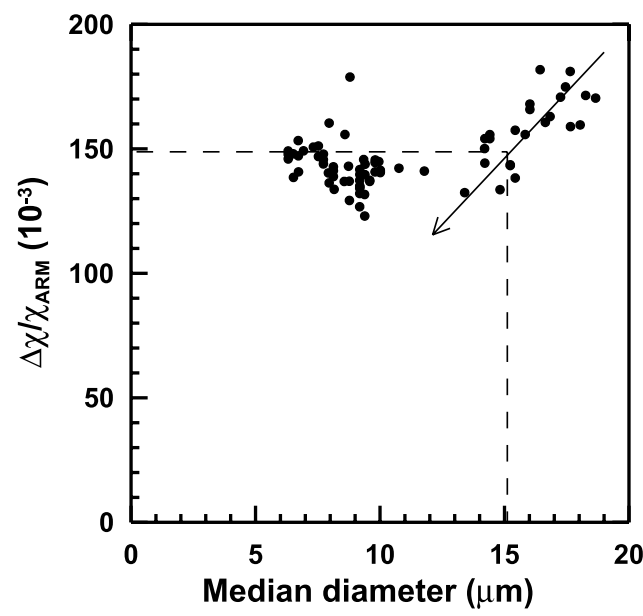

Figure 12. Correlation between $\Delta \chi / \chi_{\text {ARM }}$ and median grain size of silts by Chen et al. [1999]. The arrow shows that with decreasing median grain sizes of the clay particles, the grain sizes of the ARM and $\chi$ carriers simultaneously decrease, indicating that variations in grain sizes of both clay particles and ARM and $\chi$ carriers are probably controlled by the same processes. 
remains relatively stable even though the concentration of these grains (indicated by ARM, Figure 2) still positively correlates to the pedogenic degree.

[63] In the natural loess samples the magnetic particles are, in fact, an assemblage of magnetite, maghemite, goethite and hematite, with a wide distribution of grain sizes from SD to MD. Among them, PSD and MD grains are of aeolian origin. However, ambiguities remain as to the origin of the SD or finer PSD grains (e.g., $<1 \mu \mathrm{m}$ ), for the loess sample. They could possibly originate from various combinations of at least three mechanisms, aeolian inputs, pedogenesis, and low-temperature oxidation.

[64] Pedogenesis uniformly produces magnetic grains less than $100 \mathrm{~nm}$ with $\Delta \chi_{/} / \chi_{\text {ARM }}$ of $\sim 0.15$, apparently different from the $100-300 \mu \mathrm{m}$ particles. Therefore the finer grains in loess are not produced by pedogenesis. Furthermore, in Figure 6 we note that $\operatorname{SIRM}_{\mathrm{Re}}$ shows quite different behavior compared to the other parameters for the loess sample. There is no relationship between the variations in $\mathrm{SIRM}_{\mathrm{Re}}$ and $\mathrm{ARM}_{\mathrm{Re}}$. SIRM is carried by coarser PSD/MD grains. If the finer-grained (100-300 nm) ARM carriers are produced by low-temperature oxidation probably as maghemite rims on magnetite particles, then we would expect a systematic relationship between ARM and SIRM if they are controlled by the maghemite rim and the magnetite core, respectively.

[65] The unrelated behavior between $\mathrm{ARM}_{\mathrm{Re}}$ and $\mathrm{SIRM}_{\mathrm{Re}}$ strongly suggests that they are carried by independent sources, thus these finer-grained particles must originate from the aeolian source. The grain sizes of 100-300 $\mathrm{nm}$ are the lower size limits for the magnetic particles from aeolian inputs for these two profiles.

[66] The variations in $\Delta \chi_{X} / \chi_{\text {ARM }}$ for the less altered loess samples in zone I are believed to be independent of the weak pedogenesis. Figure 12 shows the correlation between $\Delta \chi_{X} / \chi_{\text {ARM }}$ and the median size of silts [Chen et al., 1999] (a winter monsoon intensity proxy) from the YB section. Clearly, there exists a strong linear trend between these two parameters when the median diameter is between $\sim 15$ and $20 \mu \mathrm{m}$, corresponding to the loess unit. We therefore conclude that the winter monsoon wind strength influences not only the median grain size of the aeolian clay minerals but also the grain-size size distribution of the aeolian ferrimagnetic minerals during transportation.

\subsection{Comparison With the Other Results}

[67] To confirm and extend our current model, we compare previously published results from a loess profile at Roxolany, eastern Europe by Evans and Heller [2003]. This profile is one of the most complete Quaternary records in the Black Sea area. Therefore comparison of the European and the Chinese loess results will improve our understanding of the mechanisms of pedogenesis at different sites.

[68] It is noted that the European loess/paleosol sequences present a susceptibility enhancement pattern similar to the Chinese loess, namely, higher susceptibility is found in paleosols. After removing the high-field susceptibility ( $\left.\chi_{\text {para }}\right)$, Evans and Heller [2003] revealed a step-like $\chi / \chi_{\text {ARM }}$ pattern, with higher $\chi / \chi_{\text {ARM }}(\sim 0.13)$ and lower $\chi / \chi_{\text {ARM }}$ $(\sim 0.1-0.11)$ below and above $\sim 19 \mathrm{~m}$, respectively. We believe that this first-order dramatic change in $\chi / \chi_{\text {ARM }}$ could reflect large-scale fluctuations in the source material even though the authors did not make this conclusion. At the upper part of the profile, a positive correlation can be observed between $\chi / \chi_{A R M}$ and $\chi$, consistent with our results of samples in zone III, indicating the gradually increasing contribution of SP grains to the bulk $\chi$.

[69] The loess $X / \chi_{\text {ARM }}$ ratios of Roxolany $(\sim 0.1-0.11)$ [Evans and Heller, 2003] are lower than those of the YC and JZT sections $(\sim 0.24-0.4)$. This is most probably because the Roxolany loess corresponds to the Chinese loess of zone II, where the loess units have been affected by pedogenesis but without an apparent increase in $\chi$.

[70] The consistency of variations in both $\chi$ (high $\chi$ for paleosols and low $\chi$ for the loess units) and $\chi / \chi_{\text {ARM }}$, namely a positive correlation between $\chi / \chi_{A R M}$ and $\chi$, strongly suggests that pedogenesis of both the Chinese loess and European loess (Roxolany) could be described by the same process.

\section{Conclusions}

[71] By using the parameter $\Delta \chi / \chi_{\mathrm{ARM}}$ and controlled heating experiments, this study confirms the idea that the susceptibility enhancement of the Chinese loess/paleosol sequences is caused by increasing concentration of SP + SD grains during pedogenesis. Because the magnetic properties of particles spanning the SP/SD threshold are not fully determined yet, we do not intend to clearly distinguish these particles from the stable SD particles because they are inherently interlinked by their mode of formation. We estimate that upper limits of SP grains contribution to the bulk susceptibility are $40-45 \%$. We propose that the absolute $\chi_{f d}$ without normalization is a more reliable parameter with which to quantify $\chi_{\mathrm{sp}}$.

[72] Second, loess susceptibility is carried by coarser grained (PSD, $>100-300 \mathrm{~nm}$ ) particles. The 100-300 nm grain size is believed to be the lowest significant grain size of the magnetic particles carried from the aeolian source. Although some portion of SP + SD grains may be also of aeolian origin, they are only present in minor amounts and do not significantly affect the magnetic properties.

[73] Third, for the mature paleosols, the $\chi / \chi_{\text {ARM }}$ ratios are independent of variations in susceptibility, indicating that only changes in concentration of the pedogenic SD + SP magnetic grains account for the susceptibility changes. In contrast, the large changes in $\chi / \chi_{\text {ARM }}$ for the less pedogenically altered loess units may be a sensitive indicator for tracing the subtle changes in the aeolian sources. However, this needs further confirmation, e.g., detailed studies on the L1 units with high deposition rate and low pedogenic effects from profiles in the western loess plateau, and will be covered in future research.

[74] Fourth, we propose an important criterion, comparison of thermal behavior of $\chi, \mathrm{ARM}_{\mathrm{Re}}$, and $\mathrm{SIRM}_{\mathrm{Re}}$, for using interparametric ratios $\left(\Delta \chi / \chi_{\text {ARM }}, \Delta \chi / S I R M\right.$, etc. $)$ to estimate magnetic grain size. Additional constraints come from magnetic extract efficiencies (EEs). Only those magnetic parameters carried by similar particles and with comparable EEs should be normalized against each other and further calibrated by the corresponding synthetic curves. For example, in this study, we suggest that $\Delta x /$ $\chi_{\text {ARM }}$ rather than $\chi / S I R M$ is suitable for this purpose, especially for mature paleosols. 
[75] Finally, this study interprets the pathway of susceptibility enhancement by a consistent model defined by a plot of $\Delta \mathrm{X} / \mathrm{X}$ ARM versus $\Delta \mathrm{X}$. Results reveal that susceptibility is systematically enhanced from zone I to zone IV for all the profiles.

\section{Notation}

SP superparamagnetic particles $(<30 \mathrm{~nm})$.

SD single-domain particles $(30-100 \mathrm{~nm})$.

PSD pseudosingle-domain particles $(100 \mathrm{~nm}$ to $30 \mu \mathrm{m})$.

MD multidomain particles $(>30 \mu \mathrm{m})$.

$T_{\text {tr }}$ maximum temperature for each thermal treatment, prior to magnetic measurement at room temperature.

$\chi$ mass-specific magnetic susceptibility $\left(\mathrm{m}^{3} \mathrm{~kg}^{-1}\right)$

$\chi_{\text {para }}$ susceptibility carried by paramagnetic particles. Generally it is obtained from the high-field slope of the hysteresis loops.

$\chi_{\text {SP }}$ susceptibility carried by SP grains.

$\chi>S P$ susceptibility carried by grains (SD + PSD + MD) coarser than SP particles.

$\chi_{\text {ferri }} \chi-\chi_{\text {para }}$, magnetic susceptibility carried by ferrimagnetic minerals $\left(\mathrm{m}^{3} \mathrm{~kg}^{-1}\right)$, including contributions from both SP and coarser-grained magnetic particles.

$\chi_{0}$ background $\chi$ obtained by extrapolating the linear trend between $\chi$ and ARM to the point where ARM is zero $\left(\mathrm{m}^{3} \mathrm{~kg}^{-1}\right)$, consisting of $\chi_{\text {para }}$ and $\chi_{\text {SP,loess. }}$.

$\Delta \chi \quad$ difference between the bulk susceptibility and $\chi_{0}$ $\left(\mathrm{m}^{3} \mathrm{~kg}^{-1}\right)$.

$\chi_{\mathrm{fd}}$ difference between susceptibility measured at $40 \mathrm{~Hz} 100 \% *\left(\mathrm{X}_{40 \mathrm{~Hz}}\right)$ and $4000 \mathrm{~Hz} \mathrm{100 \%}$ * $\left(\mathrm{X}_{4000 \mathrm{~Hz}}\right)$.

$\chi_{\mathrm{fd}} \%$ frequency-dependent magnetic susceptibility expressed as $\left(\chi_{40 \mathrm{~Hz}}-\chi_{4000 \mathrm{~Hz}}\right) / \chi_{4000 \mathrm{~Hz}}$.

ARM anhysteretic remanent magnetization $\left(\mathrm{A} \mathrm{m}^{2}\right.$ $\mathrm{kg}^{-1}$ ).

$\mathrm{ARM}_{\mathrm{Re}} \quad \mathrm{ARM}$ imparted at room temperature after each thermal treatment $\left(\mathrm{A} \mathrm{m}^{2} \mathrm{~kg}^{-1}\right)$.

XARM field-normalized ARM $\left(\mathrm{m}^{3} \mathrm{~kg}^{-1}\right)$.

$\chi / \chi_{\text {ARM }}$ ratio of $\chi$ and $\chi_{\text {ARM }}$.

SIRM saturation isothermal remanent magnetization (A $\mathrm{m}^{2} \mathrm{~kg}^{-1}$ ).

$\mathrm{SIRM}_{\mathrm{Re}}$ SIRM imparted at room temperature after each thermal treatment $\left(\mathrm{A} \mathrm{m}^{2} \mathrm{~kg}^{-1}\right)$.

[76] Acknowledgments. We thank B. Guo for sampling from YC section and B. Carter-Stiglitz for sampling from YB and JZT sections. We are also grateful to Ö. Özdemir for comments on the thermal stability of finer-grained maghemite. T. Rolph and F. Oldfield reviewed this manuscript and their comments are appreciated. This study was supported by NSF grants EAR 0003421 and EAR/IF 0218384, the National Science Foundation of China (NSFC) (40221402), and NSFC 40125001. All rock magnetic measurements were measured at the Institute for Rock Magnetism (IRM), which is supported by the W. M. Keck Foundation, the Earth Science Division of the U.S. National Science Foundation, and the University of Minnesota. This is IRM publication 0306.

\section{References}

An, Z. S., and S. C. Porter (1997), Millennial-scale climatic oscillations during the last interglaciation in central China, Geology, 25, 603-606.

Banerjee, S. K., and C. P. Hunt (1993), Separation of local signals from the regional paleomonsoon record of the Chinese loess plateau: A rockmagnetic approach, Geophys. Res. Lett., 20, 843-846.
Banerjee, S. K., J. King, and J. Marvin (1981), A rapid method for magnetic granulometry with applications to environmental studies, Geophys. Res. Lett., 8, 333-336.

Beget, J. E., D. B. Stone, and D. B. Hawkins (1990), Paleoclimatic forcing of magnetic susceptibility variations in Alaska loess during the late Quaternary, Geology, 18, 40-43.

Chen, F. H., J. Bloemendal, Z. D. Feng, J. M. Wang, E. Parker, and Z. T. Guo (1999), East Asian monsoon variations during oxygen isotope stage 5: Evidence from the northwestern margin of the Chinese loess plateau, Ouat. Sci. Rev., 18, 1127-1135.

Chlachula, J., M. E. Evans, and N. W. Rutter (1998), A magnetic investigation of a late Quaternary loess/palaeosol record in Siberia, Geophys. J. Int., 132, 128-132.

Cui, Y., K. L. Verosub, and A. P. Roberts (1994), The effect of low-temperature oxidation on large multi-domain magnetite, Geophys. Res. Lett., $21,757-760$.

Dankers, P. H. M. (1978), Magnetic properties of dispersed natural ironoxides of known grain size. Ph.D. dissertation, Univ. of Utrecht, Utrecht, Netherlands.

Day, R., M. Fuller, and V. A. Schmidt (1977), Hysteresis properties of titanomagnetites: Grain-size and composition dependence, Phys. Earth Planet. Inter., 13, 260-267.

Dearing, J. A., R. J. L. Dann, K. Hay, J. A. Lees, P. J. Loveland, B. A. Maher, and K. O'Grady (1996), Frequency-dependent susceptibility measurements of environmental materials, Geophys. J. Int., 124 , $228-240$.

Ding, Z. L., E. Derbyshire, S. L. Yang, Z. W. Yu, S. F. Xiong, and T. S. Liu (2002), Staked 2.6-Ma grain size record from the Chinese loess based on five sections and correlation with the deep-sea $\Delta^{18} \mathrm{O}$ record, Paleoceanography, 17(3), 1033, doi:10.1029/2001PA000725.

Dunlop, D. (2002a), Theory and application of the Day plot $\left(M_{\mathrm{rs}} / M_{s}\right.$ versus $\left.H_{\mathrm{cr}} / H_{c}\right): 1$. Theoretical curves and tests using titanomagnetite data, J. Geophys. Res., 107(B3), 2056, doi:10.1029/2001JB000486.

Dunlop, D. (2002b), Theory and application of the Day plot $\left(M_{\mathrm{rs}} / M_{s}\right.$ versus $\left.H_{\mathrm{cr}} / H_{c}\right): 2$. Application to data for rocks, sediments, and soils, J. Geophys. Res., 107(B3), 2057, doi:10.1029/2001JB000487.

Evans, M. E. (2001), Magnetoclimatology of aeolian sediments, Geophys. J. Int., 14, 495-497.

Evans, M. E., and F. Heller (2001), Magnetism of loess/paleosol sequences: Recent developments, Earth Sci. Rev., 54, 129-144.

Evans, M. E., and F. Heller (2003), Environmental Magnetism: Principles and Applications of Enviromagnetics, Academic, San Diego, Calif

Fang, X. M., J. J. Li, R. Van der Voo, C. M. Niocaill, X. R. Dai, R. A. Kemp, E. Derbyshire, J. X. Cao, J. M. Wang, and G. Wang (1997), A record of the Blake event during the last interglacial paleosol in the western loess plateau of China, Earth Planet. Sci. Lett., 146, 73-82.

Fang, X. M., J. J. Li, S. K. Banerjee, M. J. Jackson, E. A. Oches, and R. Van der Voo (1999), Millennial-scale climatic change during the last interglacial period; superparamagnetic sediment proxy from paleosol S1, western Chinese loess plateau, Geophys. Res. Lett., 26, 2485-2488.

Forster, T., and F. Heller (1997), Magnetic enhancement paths in loess sediments from Tajikistan, China, and Hungary, Geophys. Res. Lett., 24, 17-20.

Forster, T., M. E. Evans, and F. Heller (1994), The frequency dependence of low field susceptibility in loess sediments, Geophys. J. Int., 118, 636642

Gallagher, K. J., W. Feitknecht, and U. Mannweiler (1968), Mechanism of oxidation of magnetite to $\gamma-\mathrm{Fe}_{2} \mathrm{O}_{3}$, Nature, 217, 1118-1121.

Guo, B., R. X. Zhu, Z. L. Ding, and J. M. Sun (1999), Upper Jaramillo polarity transition and short geomagnetic event recorded in a loess section at Jingbian, northern China, Chin. Sci. Bull., 44, 1907-1914.

Heller, F., and M. E. Evans (1995), Loess magnetism, Rev. Geophys, 33 $211-240$.

Heller, F., and T. S. Liu (1982), Magnetostratigraphical dating of loess deposits in China, Nature, 300, 431-433.

Heller, F., and T. S. Liu (1984), Magnetism of Chinese loess deposits, Geophys. J. R. Astron. Soc., 77, 125-141.

Heller, F., and T. S. Liu (1986), Palaeoclimatic and sedimentary history from magnetic susceptibility of loess in China, Geophys. Res. Lett., 13, $1169-1172$

Hunt, A. (1986), The application of mineral magnetic methods to atmospheric aerosol discrimination, Phys. Earth Planet. Inter., 42, 10-21.

Hunt, C. P., S. K. Banerjee, J. M. Han, P. A. Solheid, E. Oches, W. W. Sun, and T. S. Liu (1995), Rock-magnetic proxies of climate change in the loess-paleosol sequences of the western loess plateau of China, Geophys. J. Int., 123, 232-244.

Kemp, R. A., E. Derbyshire, and X. M. Meng (2001), A high-resolution micromorphological record of changing landscapes and climates on the western loess plateau of China during oxygen isotope stage 5, Palaeogeogr. Palaeoclimatol. Palaeoecol., 170, 157-169. 
King, J., S. K. Banerjee, J. Marvin, and Ö. Özdemir (1982), A comparison of different magnetic methods for determining the relative grain size of magnetite in natural materials: Some results from lake sediments, Earth Planet. Sci. Lett., 59, 404-419.

Kosterov, A. (2002), Low-temperature magnetic hysteresis properties of partially oxidized magnetite, Geophys. J. Int., 149, 796-804.

Kukla, G., F. Heller, X. M. Liu, T. C. Xu, T. S. Liu, and Z. S. An (1988), Pleistocene climates in China dated by magnetic susceptibility, Geology, $16,811-814$.

Lagroix, F., and S. K. Banerjee (2002), Paleowind directions from the magnetic fabric of loess profiles in central Alaska, Earth Planet. Sci. Lett., 195, 99-112.

Liu, Q. S., S. K. Banerjee, R. X. Zhu, and Y. X. Pan (2002), Effects of low-temperature oxidation on the natural remanent magnetization of the Chinese loess, Chin. Sci. Bull., 47, 2100-2105.

Liu, X. M., P. Hesse, and T. Rolph (1999a), Origin of maghaemite in Chinese loess deposits: Aeolian or pedogenic?, Phys. Earth Planet. Inter, 112, 191-201.

Liu, X. M., P. Hesse, T. Rolph, and J. E. Begét (1999b), Properties of magnetic mineralogy of Alaskan loess, Quat. Int., 62, 93-102.

Liu, X. M., T. Rolph, Z. S. An, and P. Hesse (2003), Paleoclimatic significance of magnetic properties on the Red Clay underlying the loess and paleosols in China, Palaeogeogr. Palaeoclimatol. Palaeoecol., 199, $153-166$.

Maher, B. A. (1988), Magnetic properties of some synthetic sub-micron magnetites, Geophys. J., 94, 83-96.

Maher, B. A. (1998), Magnetic properties of modern soils and Quaternary loessic paleosols: Paleoclimatic implications, Palaeogeogr. Palaeoclimatol. Palaeoecol., 137, 25-54.

Maher, B. A., and R. Thompson (1991), Mineral magnetic record of the Chinese loess and paleosol, Geology, 19, 3-6.

Maher, B. A., and R. Thompson (1992), Paleoclimatic significance of the mineral magnetic record of the Chinese loess and paleosols, Quat. Res. $37,155-170$

Maher, B. A., and R. Thompson (1995), Paleorainfall reconstructions from pedogenic magnetic susceptibility variations in the Chinese loess and paleosols, Quat. Res., 44, 383-391.

Maher, B. A., and R. Thompson (1999), Quaternary Climates, Environments, and Magnetism, Cambridge Univ. Press, New York.

Mullins, C. E. (1977), Magnetic susceptibility of the soil and its significance in soil science: A review, J. Soil Sci., 28, 223-246.

Mullins, C. E., and M. S. Tite (1973), Magnetic viscosity, quadrature susceptibility, and frequency dependence of susceptibility in single-domain assemblies of magnetite and maghemite, J. Geophys. Res., 78, 804-809.

Nabel, P. (1993), The Brunhes-Matuyama boundary in Pleistocene sediments of Buenos Aires Province, Argentina, Quat. Int., 17, 79-85.

Oldfield, F., B. A. Maher, J. Donoghue, and J. Pierce (1985), Particle-size related, mineral magnetic source-sediment linkages in the Rhode River catchment, Maryland, USA, J. Geol. Soc. London, 142, 1035-1046.

Özdemir, Ö., and S. K. Banerjee (1982), A preliminary magnetic study of soil samples from west-central Minnesota, Earth Planet. Sci. Lett., 59 $393-403$

Pan, Y. X., R. X. Zhu, J. Shaw, Q. S. Liu, and B. Guo (2001), Can relative paleointensities be determined from the normalized magnetization of the wind-blown loess of China?, J. Geophys. Res., 106, 19,221-19,232.

Porter, S. C. (2001), Chinese loess record of monsoon climate during the last glacial-interglacial cycle, Earth Sci. Rev., 54, 115-128.
Schellenberger, A., F. Heller, and H. Veri (2003), Magnetostratigraphy and magnetic susceptibility of the Las Carreras loess-paleosol sequence in Valle de Tafí, Tucumán, NW-Argentina, Quat. Int., 106-107, 159-167.

Senno, H., Y. Tawara, and Y. Iida (1967), Transformation of $\gamma-\mathrm{Fe}_{2} \mathrm{O}_{3}$ into $\alpha-\mathrm{Fe}_{2} \mathrm{O}_{3}, J$. Apply Phys., 6, 1347-1348.

Stephenson, A. (1971), Single domain grain distributions: I. A method for the determination of single domain grain distributions, Phys. Earth Planet. Inter., 4, 353-360.

Sun, J. M., and T. S. Liu (2000), Multiple origins and interpretations of the magnetic susceptibility signal in Chinese wind-blown sediments, Earth Planet. Sci. Lett., 180, 287-296.

Sun, W. W., S. K. Banerjee, and C. P. Christopher (1995), The role of maghemite in the enhancement of magnetic signal in the Chinese loess-paleosol sequence: An extensive rock magnetic study combined with citrate-bicarbonate-dithionite treatment, Earth Planet. Sci. Lett., $133,493-505$.

Thompson, R., J. Bloemendal, J. A. Dearing, F. Oilfield, T. A. Rummery, J. C. Stober, and G. M. Turner (1980), Environmental applications of magnetic measurements, Science, 207, 481-486.

van Velzen, A. J., and M. J. Dekkers (1999), Low-temperature oxidation of magnetite in loess-paleosol sequences: A correction of rock magnetic parameters, Stud. Geophys. Geod., 43, 357-375.

Verosub, K. L., P. Fine, M. J. Singer, and J. Tenpas (1993), Pedogenesis and paleoclimate: Interpretation of the magnetic susceptibility record of Chinese loess-paleosol sequences, Geology, 21, 1011-1014.

Worm, H.-U. (1998), On the superparamagnetic-stable single domain transition for magnetite, and frequency dependence of susceptibility, Geophys. J. Int., 133, 201-206.

Worm, H.-U., and M. J. Jackson (1999), The superparamagnetism of Yucca Mountain Tuff, J. Geophys. Res., 104, 25,415-25,425.

Zhou, L. P., F. Oldfield, A. G. Wintle, S. G. Robinson, and J. T. Wang (1990), Partly pedogenic origin of magnetic variations in Chinese loess, Nature, 346, 737-739.

Zhu, R. X., Y. X. Pan, and Q. S. Liu (1999), Geomagnetic excursions recorded in Chinese loess in the last 70,000 years, Geophys. Res. Lett., 26, 505-508

Zhu, R. X., A. Kazansky, G. Matasova, B. Guo, V. Zykina, E. Petrovsky, and N. Jordanova (2000), Rock-magnetic investigation of Siberia loess and its implication, Chin. Sci. Bull., 45, 2192-2197.

Zhu, R. X., G. Matasova, A. Kazansky, V. Zykina, and J. M. Sun (2003), Rock magnetic record of the last glacial-interglacial cycle from the Kurtak loess section, southern Siberia, Geophys. J. Int., 152, 335-343.

S. Banerjee, M. Jackson, and Q. Liu, Institute for Rock Magnetism, Department of Geology and Geophysics, University of Minnesota, 310 Pillsbury Drive SE, Minneapolis, MN 55455, USA. (banerjee@umn.edu; irm@tc.umn.edu; liux0272@tc.umn.edu)

F. Chen, CAEP, College of Earth and Environment Science, University of Lanzhou, Lanzhou, Gansu, 73000, China. (fhchen@1zu.edu.cn)

C. Deng, Y. Pan, and R. Zhu, Paleomagnetism Laboratory, Institute of Geology and Geophysics, Chinese Academy of Sciences, Beijing, 100029, China. (cldeng@mail.igcas.ac.cn; yxpan@mail.igcas.ac.cn; rxzhu@mail. igcas.ac.cn)

B. Maher, CEMP, Lancaster Environment Center, Geography Department, Lancaster University, Lancaster, LA1 4YW, UK. (b.maher@ lancaster.ac.uk) 